\title{
Promises and challenges of alloy-type and conversion-type anode materials for sodiumeion batteries
}

\author{
Lichuan Wang a, b, Jolanta Swiatowska $\quad$ b, c, Sirui Dai ${ }^{\text {a }}$, Minglei Cao ${ }^{\text {a }}$, Zhicheng Zhong \\ d, Yan Shen a , Mingkui Wang a, * \\ ${ }^{a}$ Wuhan National Laboratory for Optoelectronics, Huazhong University of Science and Technology, Wuhan \\ 430074, P. R. China \\ ${ }^{b}$ China-EU Institute for Clean and Renewable Energy, Huazhong University of Science and Technology, \\ Wuhan 430074, P. R. China \\ ${ }^{c}$ PSL Research University, Chimie ParisTech-CNRS, Institut de Recherche de Chimie Paris (IRCP), 11 Rue \\ Pierre et Marie Curie, 75005 Paris, France \\ ${ }^{d}$ Hubei Key Laboratory of Low Dimensional Optoelectronic Material and Devices, Hubei University of Art \\ and Science, Longzhong Road 296, Xiangyang, \\ 441053, P. R. China
}

*Corresponding author. E-mail address: mingkui.wang@mail.hust.edu.cn (M. Wang).

\begin{abstract}
Sodium-ion batteries (SIBs) are considered as one of the most promising candidates for competing with lithium-ion batteries owing to significant natural abundance of sodium and similar reaction mechanism. The large radius of $\mathrm{Na}^{+}(1.02 \AA)$ severely impedes the electrochemical performance, especially high-rate capability and long-cycle stability of SIBs. Together with the cathode and electrolyte, the anode determines full battery's operating voltage and plays a vital role in avoiding sodium dendrite in terms of redox potential. On this account, the anode holds a prime importance toward the development of advanced SIBs with high rate capability and superior durability. Herein, we present a review on the exciting advances in alloy- and conversion-type anode materials as well as solid-electrolyte interphase layer for SIBs aiming at the improvement of rate capability and cycling life. Finally, the challenges and some of the critical issues in alloy-type and conversion-type anode materials for sodium-ion batteries are addressed.
\end{abstract}

Keywords: Sodiumeion batteries; Anode; Conversion; Alloying; Solid-electrolyte interphase layer 


\section{Introduction}

The continuously increasing demand for powering systems stimulates research towards high storage capacity system. The lithium-ion batteries (LIBs) have become one of the most successful commercialized secondary batteries. However, LIBs might be not suitable for large-scale stationary energy storage systems because of its limited Li resources and its geographical distribution in politically sensitive areas [1].

Sodium is the sixth most abundant element in the earth's crust and possesses the similar physico-chemical properties as lithium in addition to the moderate redox potential of about $2.71 \mathrm{~V}$ (vs. SHE) [2]. More importantly, the specific energy density of sodium-ion batteries (SIBs) is just about 17\% lower than LIB if practical factors (e.g., the weight of current collector) are taken into consideration, indicating that SIBs hold a great promise in the energy storage [3]. Therefore, the research interests have gradually shifted to Na-ion batteries. Fig. 1 illustrates the schematic diagram of the working principle of SIBs based on the mechanism of intercalation reaction. During the charging process, positively charged sodium ions are forced to de-intercalate from the cathode and travel through electrolytes to the anode. At the same time, charge balancing electrons pass from the cathode to the anode through the external circuit. The opposite behavior occurs in the discharging process.

As one in LIBs, graphite-based materials as anode in SIBs have also triggered numerous interests. At the beginning, the sodiumgraphite intercalation compounds were considered as unstable in conventional carbonate electrolytes [4]. Jache et al. [5] and Kim et al. [6] proposed the diglyme-based and ether-based electrolytes, in which, the stable ternary graphite intercalation compounds can be formed. Later on, Ge et al. [7] reported on 1D and 2D/3D carbon materials, which can achieve the high reversible capacity and great rate performance, respectively (324.9 $\mathrm{mAh} \mathrm{g}^{1}$ at $0.1 \mathrm{~A} \mathrm{~g}^{1}$ for $1 \mathrm{D} ; 92.2 / 90.9 \mathrm{mAh} \mathrm{g}^{1}$ at $5.0 \mathrm{~A} \mathrm{~g}^{1}$ for 2D/3D). Some heteroatoms such as $\mathrm{P}$ [8], S and $\mathrm{N}$ [9] were also doped into carbon materials with the aim of improving the electrode capability. The conversion from 0D carbon dots to 2D nanosheets doped with phosphorus (P-CNSs) was realized by Hou et al. for the first time [8]. The interlayer

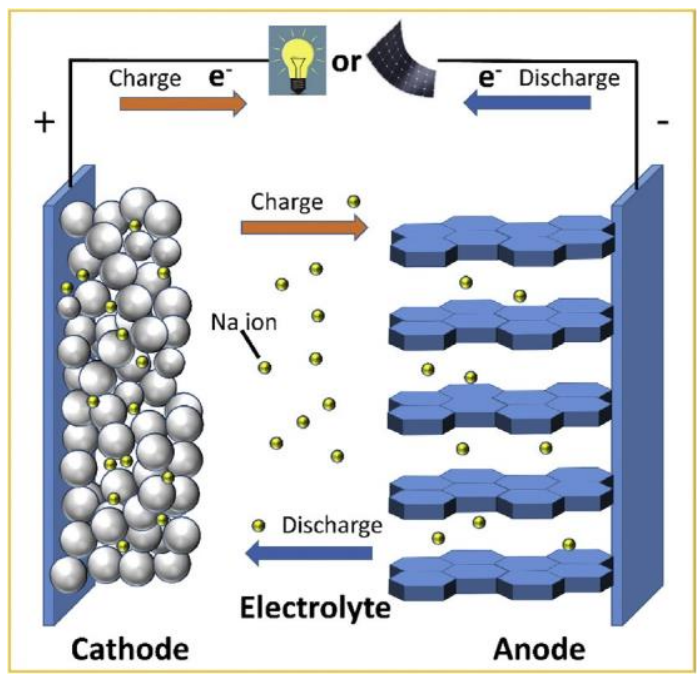

Fig. 1. The schematic diagram of working mechanism of sodium-ion battery. 
distance was enlarged because of the doping of P, then the P-CNSs achieved a considerable capacity of 108 $\mathrm{mAh} \mathrm{g}^{1}$ even at $20 \mathrm{~A} \mathrm{~g}^{1}$. Similarly, the precursors have a great influence on the morphology, specific surface area and sodium storage performances of S-doped carbon materials. According to the sodium-ion storage test, a content of 5.4\% (mass percentage) has been considered to be the most suitable in carbon materials compared with $4.6 \%$ and $5.6 \%$ [9]. Though many advances have been made in application of graphite as anode material for SIBs, graphite cannot reach the high capacity as required for SIB, which is hindered by its intrinsic structure. Herein, it is imperative to develop stable anode materials with high discharging capacity and robust durability toward the practical applications.

So far, the intercalation type anode materials exhibit better stability performance than conversion- and alloying-type counterparts. Intercalation compounds usually possess layered structures and thus, sodium ions can be able to embed in layers during the charging process. The most striking advantages of intercalation type materials reflect in providing a suited insertion potential and superior structural stability, ensuring the safety and long-term cycling. Most titanium-based oxides such as $\mathrm{TiO}_{2}$ [10], $\mathrm{Na}_{2} \mathrm{Ti}_{3} \mathrm{O}_{7}$ [11] and $\mathrm{Li}_{4} \mathrm{Ti}_{5} \mathrm{O}_{12}$ [12] reserve sodium ions through intercalation chemistry and thus deliver excellent cycling life (>1000 cycles). Nevertheless, in the light of finite number of storage sites in their crystalline structures, most of intercalationtype materials usually show comparatively small reversible capacities of less than $300 \mathrm{mAh} \mathrm{g}^{1}$ [13-22]. Additionally, poor electron conductivity of most layered titanium-based oxides gives rise to another obstacle for the migration of electrons $[11,23,24]$. These factors are responsible for sluggish $\mathrm{Na}^{+}$reaction kinetics which significantly restricts the rate performance of SIBs.

In order to achieve the superior electrochemical performance of SIBs, researchers gradually began to pay more attention to the anode materials characterized by high specific capacities and appropriate redox potentials. Considering the low energy density of insertion-type electrodes determined by their intrinsic structures, alloying- and conversion-based materials are certainly of great priority. Compared with insertiontype electrodes, the biggest advantage of alloying- and conversion-based materials is their high theoretical specific capacities (Fig. 2). These kinds of anodes are mainly composed by elements from Group IVA and VA as well as their compounds (e.g., oxides, selenides, and sulfides), which can store sodium ions by forming Na-rich metallic compounds such as

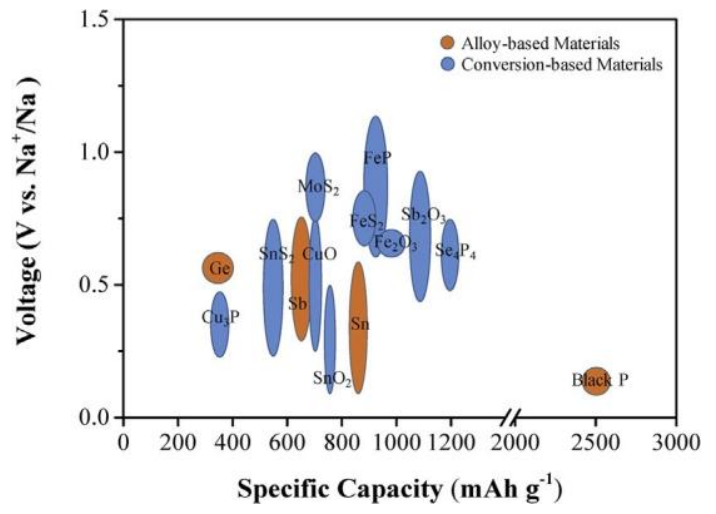

Fig. 2. The average discharging potential versus theoretical specific capacity plot of alloy- and conversionbased materials as anodes for SIBs. 
$\mathrm{Na}_{15} \mathrm{Sn}_{4}, \mathrm{Na}_{3} \mathrm{Sb}$, and $\mathrm{Na}_{3} \mathrm{P}$ through alloying or conversion reactions [25,26]. For example, Sb shows a theoretical capacity of $660 \mathrm{mAh} \mathrm{g}^{1}$ (based on the formation of full sodiation product of $\mathrm{Na}_{3} \mathrm{Sb}$ ) [27]. P exhibits potentially the highest theoretical capacity of $2596 \mathrm{mAh} \mathrm{g}^{1}$ by forming $\mathrm{Na}_{3} \mathrm{P}$ [28]. Furthermore, their working potentials are suitable for the anode in SIBs, which are just slightly higher than typical insertion-type anodes (i.e., hard carbon and Tibased compounds). Fig. 3 depicts the relative energy level diagram of the electrolyte, anode and cathode. If the Fermi energy of the anode $\left(\mathrm{m}_{\mathrm{A}}\right)$ is above the lowest unoccupied molecular orbital of the electrolyte (LUMO), the electrolyte would be reduced (i.e., the formation of solid-electrolyte interphase (SEI) layer) [29]. Similarly, the cathode would be oxidized when the Fermi energy of the cathode $\left(m_{C}\right)$ is below the highest occupied molecular orbital of the electrolyte (HOMO). Thus, the ideal situation is that $\mathrm{m}_{\mathrm{A}}$ and $\mathrm{m}_{\mathrm{C}}$ should fall in the working potential window of the electrolyte, which means that the electrochemical potential of anode should be as low as possible but kept above LUMO of the electrolyte. According to Fig. 2, it can be concluded that the working potentials of alloy- and conversion-based materials are appropriate to be the anode in SIBs. It also should be noted that the high energy density would compensate the capacity loss originated from the higher working potential than that of insertion-type materials.

Although these alloy- and conversion-based materials have numerous advantages mentioned above, several issues have to be solved before their practical applications [30,31]. The key barrier that impedes further application of these anode materials is significant capacity loss upon cycling caused by several reasons [32,33]. Firstly, a large volume variation results in aggregation and pulverization of active materials, which may lead to the weak electrical contact of pulverized electrode material and the slow

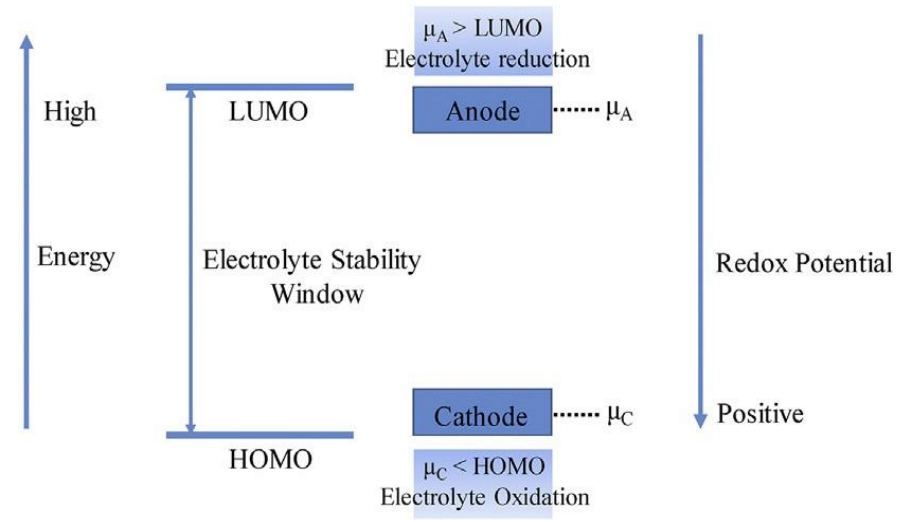

Fig. 3. Schematic energy level diagram of the electrolyte, cathode and anode, indicating that the $\mathrm{m}_{\mathrm{A}}$ higher than LUMO and/or $m_{C}$ lower than HOMO requires a kinetic stability by the formation of SEI layer (electrolyte reduction).

reaction kinetics. Secondly, SEI layer forms constantly on the surface of the newly exposed active material during (dis)charging. The resultant thick SEI and/or insulating layers would largely retard the charge transfer and lead to sharp capacity decay [34-36]. Thirdly, because of the unstable SEI film, which can easily dissolve, a low initial Coulombic efficiency can be observed, which turns out to be a crucial issue for the application of SIBs. Moreover, a low electron diffusion co-efficiency of these materials is another critical issue restricting their cycle life and delivered capacity at high rates [33,37]. Table 1 lists the reaction mechanisms of typical alloy- and conversion-based materials as well as the electrical conductivity, capacity and volume change. 
With the aim of improving the electrochemical performance, several approaches have been developed to mitigate the negative effects of volume variations and to improve the electronic conductivity of alloy- and conversion-based electrode materials. For example, novel nanostructured anodes can not only better withstand the stress and strain caused by the pulverization, but also reduce the ionic diffusion distance. A further inclusion of carbonbased materials helps to suppress the volume change and particle aggregation of active substance during the sodiation/desodiation process, thus contributes in solving the problems associated with loss of electrical conductivity.

Engineering metallic or nonmetallic alloys in the compounds such as $\mathrm{M}-\mathrm{Sn} / \mathrm{P} / \mathrm{Sb}$ is another promising way to explore the novel conversion-based materials. $\mathrm{M}$ can be an electrochemically inactive or active component for storing sodium ions. For M used as an inactive element, M/Sn composite (taking M - Sn as an example) can be produced in the initial cycle. Consequently, $\mathrm{M}$ can act as a buffer to alleviate volume expansion during (dis)charging and help to improve the system's electric conductivity [54-56]. On the other hand, when M is used as an electrochemically active element, two different metal phases would behave as the mutual matrix to each other so as to weaken the adverse influence of volume fluctuation [55,57]. Note that though pure Se possesses a good electrical conductivity $\left(\sim 10^{5} \mathrm{~S} \mathrm{~cm}^{1}\right)$, it suffers from the fast capacity fading mainly due to the dissolution of polyselenide intermediates in electrolytes [58,59]. On the contrary, Se-alloying compounds can show remarkable cycling stability on account of beneficial reaction mechanisms by forming directly $\mathrm{Na}_{2} \mathrm{Se}_{\text {without }}$ the generation of polysenenide intermediates $[60,61]$.

Table 1 Summary of alloy- and conversion-type based electrode materials for sodium-ion batteries (metal sulfides based on mixed reactions).

\begin{tabular}{|c|c|c|c|c|c|c|}
\hline $\begin{array}{l}\text { Type of reaction } \\
\text { mechanism }\end{array}$ & Material & $\begin{array}{l}\text { Electrical } \\
\text { conductivity } \\
\left(\mathrm{S} \mathrm{cm}^{-1}\right)\end{array}$ & $\begin{array}{l}\text { Theoretical } \\
\text { capacity } \\
\left(\mathrm{mAh} \mathrm{g}^{-1}\right)\end{array}$ & $\begin{array}{l}\text { Volume } \\
\text { change }\end{array}$ & $\begin{array}{l}\text { Potential } \\
\text { window } \\
\text { (V) }\end{array}$ & $\begin{array}{c}\text { Initial } \\
\text { discharging/charging } \\
\text { capacity values }\end{array}$ \\
\hline \multicolumn{7}{|l|}{ Alloying Reaction } \\
\hline \multirow[t]{4}{*}{$\mathrm{M}+\mathrm{xNa}^{+}+\mathrm{xe}^{-} \leftrightarrow \mathrm{Na}_{\mathrm{x}} \mathrm{M}$} & $\mathrm{Sb}[38]$ & $2.5 \times 10^{4}$ & 660 & $393 \%$ & $\begin{array}{l}0.01- \\
2.0\end{array}$ & $\begin{array}{c}\text { Sb-C naofibers, } \\
1280 / 610 \mathrm{mAh} \mathrm{g}^{-1} \text { at } \\
40 \mathrm{~mA} \mathrm{~g}^{-1}[38]\end{array}$ \\
\hline & $\begin{array}{l}\mathrm{Ge} \\
{[39]}\end{array}$ & $\sim 10^{-2}$ & 369 & $305 \%$ & $\begin{array}{l}0.01- \\
2.0\end{array}$ & $\begin{array}{c}\text { amorphous Ge } \\
\text { nanowire, } \\
465 / 367 \mathrm{mAh} \mathrm{g}^{-1} \\
\text { at } 37 \mathrm{~mA} \mathrm{~g}^{-1}[40]\end{array}$ \\
\hline & $\mathrm{Sn}[41]$ & $9 \times 10^{4}$ & 847 & $420 \%$ & $\begin{array}{l}0.05- \\
1.50\end{array}$ & $\begin{array}{l}\text { C/Sn/Ni/TMV1cys } \\
\text { nanorods, } \\
920 / 722 \mathrm{mAh} \mathrm{g}^{-1} \\
\text { at } 50 \mathrm{~mA} \mathrm{~g}^{-1}[41]\end{array}$ \\
\hline & $\mathrm{P}[42]$ & $10^{-14}$ & 2596 & $490 \%$ & $\begin{array}{l}0.01- \\
1.75\end{array}$ & $\begin{array}{l}\text { Black P-graphite, } \\
2786 / 2270 \mathrm{mAh} \mathrm{g}^{-1} \\
\text { at } 520 \mathrm{~mA} \mathrm{~g}^{-1}[42]\end{array}$ \\
\hline
\end{tabular}




\section{Conversion Reaction}

\begin{tabular}{|c|c|c|c|c|c|c|}
\hline $\begin{array}{c}\mathrm{MO}_{\mathrm{x}}+2 \mathrm{xNa}^{+}+2 \mathrm{xe}^{-} \\
\leftrightarrow \mathrm{xNa}_{2} \mathrm{O}+\mathrm{M}\end{array}$ & $\begin{array}{l}\mathrm{Fe}_{2} \mathrm{O}_{3} \\
{[43]}\end{array}$ & $7 \times 10^{-3}$ & 1007 & - & $\begin{array}{l}0.04- \\
3.0\end{array}$ & $\begin{array}{c}\gamma-\mathrm{Fe}_{2} \mathrm{O}_{3} @ \mathrm{C}, \\
1927 / 993 \mathrm{mAh} \mathrm{g}^{-1} \text { at } \\
200 \mathrm{~mA} \mathrm{~g}^{-1}[43]\end{array}$ \\
\hline & $\begin{array}{l}\mathrm{CuO} \\
{[44]}\end{array}$ & $0.03-1$ & 674 & - & $0-3.0$ & $\begin{array}{c}\text { CuO nanorod } \\
\text { array, } 935 / 570 \mathrm{mAh} \\
\mathrm{g}^{-1} \text { at } 20 \mathrm{~mA} \mathrm{~g}^{-1}[44]\end{array}$ \\
\hline $\begin{array}{c}\mathrm{M}_{\mathrm{x}} \mathrm{P}_{1-\mathrm{x}}+(3-\mathrm{x}) \mathrm{Na}^{+}+(3- \\
\mathrm{x}) \mathrm{e}^{-} \leftrightarrow(1-\mathrm{x}) \mathrm{Na}_{3} \mathrm{P}+\mathrm{xNa} \mathrm{Na}_{2} \mathrm{M}\end{array}$ & $\begin{array}{l}\mathrm{Se}_{4} \mathrm{P}_{4} \\
{[45]}\end{array}$ & $10^{-4}$ & 1218 & - & $\begin{array}{l}0.01- \\
3.0\end{array}$ & $\begin{array}{c}\mathrm{Se}_{4} \mathrm{P}_{4} \\
1483 / 1048 \mathrm{mAh} \mathrm{g}^{-} \\
{ }^{1} \text { at } 50 \mathrm{~mA} \mathrm{~g}^{-1}[45]\end{array}$ \\
\hline \multirow[t]{2}{*}{$\begin{array}{l}\mathrm{MP}_{x}+3 \mathrm{xNa}^{+}+3 \mathrm{xe}^{-} \\
\leftrightarrow \mathrm{xNa} \mathrm{a}_{3} \mathrm{P}+\mathrm{M}\end{array}$} & $\begin{array}{l}\mathrm{FeP} \\
{[46]}\end{array}$ & - & 924 & $\begin{array}{c}> \\
202 \%\end{array}$ & $\begin{array}{l}0.005- \\
3.0\end{array}$ & $\begin{array}{c}\text { FeP@C@graphene, } \\
995 / 656 \mathrm{mAh} \mathrm{g}^{-1} \text { at } \\
100 \mathrm{~mA} \mathrm{~g}^{-1}[46]\end{array}$ \\
\hline & $\begin{array}{l}\mathrm{Cu}_{3} \mathrm{P} \\
{[47]}\end{array}$ & - & 366 & - & $0-2.5$ & $\begin{array}{c}\mathrm{Cu}_{3} \mathrm{P} \\
433 / 349 \mathrm{mAh} \mathrm{g}^{-1} \\
\text { at } 50 \mathrm{~mA} \mathrm{~g}^{-1}[47]\end{array}$ \\
\hline
\end{tabular}

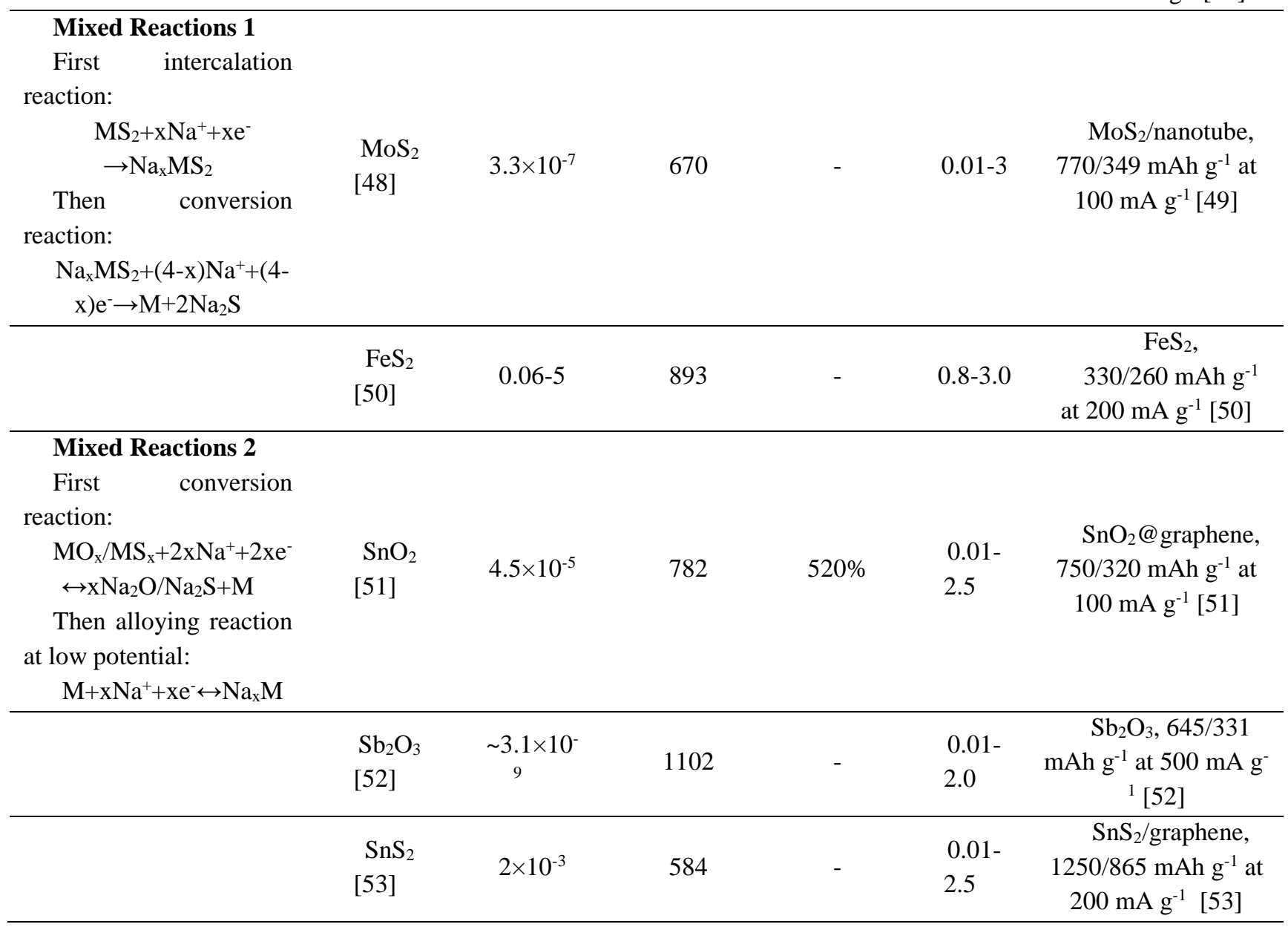

There have been many comprehensive reviews about SIBs in recent years. However, they usually focused on both cathode and anode or just specialize in a specific materials family (e.g., metal sulfides) [62]. It is 
commonly believed that at the present the anode is the biggest obstacle to achieve the commercialization of SIBs. However, there are few reviews presenting systematically in details the alloy- and conversion-type electrode materials for SIBs. Besides, most reviews do not summarize and refine the impact of SEI layer to the SIBs' electrochemical performance. On this account, this review summarizes the latest developments of alloyand conversion-type materials and the SEI layer in SIBs. To be more specific, the mechanism of Nastorage and the corresponding failure mechanisms of the selected anodes along with the effective methods to improve their electrochemical performances are discussed in details. As illustrated in Fig. 4, this review includes a description of effective approaches to improvement of anode such as the introduction of carbonbased materials, designing materials with nanostructured architecture and forming the intermetallic compounds. The formation of SEI layer and its influence on the electrochemical performances of SIBs are illustrated in a single part.

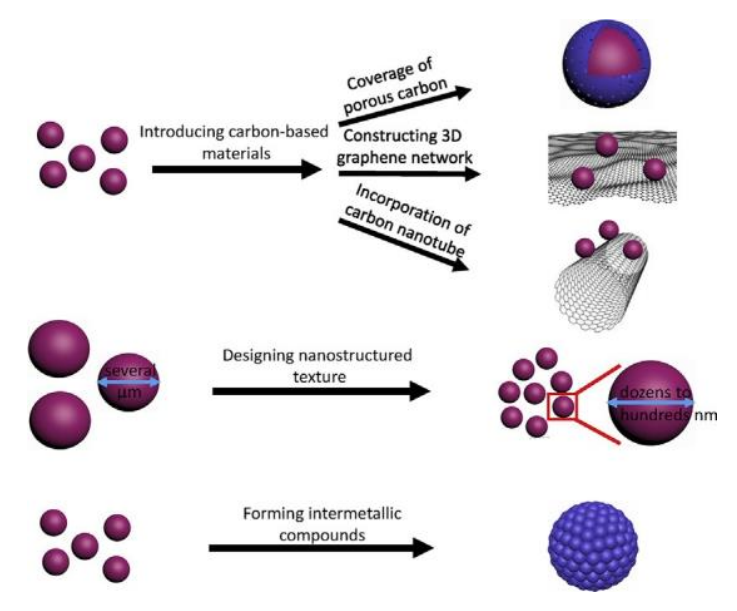

Fig. 4. Effective approaches to improve anode electrochemical performance for alloying- and conversionbased materials.

2. Anode materials based on alloying and mixed (alloying and conversion) reactions

Several elements from Group IVA (e.g., Sn) and VA (e.g., P, Sb) have been extensively studied as anode materials for SIBs owing to their high theoretical capacity and low sodiation potential. One of the main issues for this type of materials is about significant volume variation (as shown in Table 1). For this regard, we will focus on metallic (eg., Sn, Sb) and nonmetallic elements (eg., P) as well as their intermetallic compounds.

\subsection{Sn-based materials}

Early in 2011, first-principles calculations (DFT) calculation revealed the formation of different $\mathrm{Na}-\mathrm{Sn}$ phases with following sequence: $\mathrm{NaSn}_{5}, \mathrm{NaSn}, \mathrm{Na}_{9} \mathrm{Sn}_{4}$, and $\mathrm{Na}_{15} \mathrm{Sn}_{4}$ [32]. Then, the formation of $\mathrm{Na}_{15} \mathrm{Sn}_{4}$ in full sodiation state was further experimentally observed by X-ray diffraction (XRD) but not the intermediate phases [63]. Ellis et al. proposed a different mechanism for Sn sodiation via in situ XRD measurements at ambient temperature [64]. The four voltage plateaus observed during the sodiation process attributed to formation of four two-phase materials. Therefore, Ellis et al. suggested that four Na-Sn binary alloys were formed but actually only the full-sodiated product of $\mathrm{Na}_{15} \mathrm{Sn}_{4}$ was detected by XRD because other Na-Sn alloys are unstable or amorphous. Simultaneously, in situ TEM studies of sodiation process of Sn revealed 
that crystalline $\mathrm{Sn}$ undergoes a two-step sodiation: a twophase transformation to form noncrystalline $\mathrm{NaSn}_{2}$ followed by a single-phase conversion to create $\mathrm{Na}_{9} \mathrm{Sn}_{4}$ and $\mathrm{Na}_{3} \mathrm{Sn}$, accompanied by a volume expansion of about $60 \%$ and $420 \%$, respectively [65]. Fig. 5 shows the schematic diagram of this mechanism. Due to disparity of current theoretical and experimental studies, it is necessary to deeply study the mechanisms of sodium insertion into Sn to clearly understand its electrochemical process.

Komaba et al. first reported highly reversible Sn electrodes could be achieved when fluoroethylene carbonate (FEC)-added polyacrylate (PAA) was used as a binder instead of polyvinylidene fluoride (PVDF) [63]. Indeed, the Sn-PAA system exhibited a reversible capacity of $500 \mathrm{mAh} \mathrm{g}^{1}$ for 20 cycles. From then on, intensive studies have been devoted to suppress volume changes, ensure a good contact between active material and current collector, and boost reaction kinetics of $\mathrm{Sn}$ with the purpose of achieving high rate capability and long-cycle life. Nanostructuration of electrode materials is a powerful strategy to buffer the volume changes and to resist strong mechanical stresses induced by sodiation/desodiation process and shorten ion diffusion pathways. Recently, it was reported that Sn nanofibers with a high aspect ratio prepared by template-free electrodeposition process exhibited a high reversible capacity in large current density (about $260 \mathrm{mAh} \mathrm{g}^{1}$ at $5 \mathrm{C}$ ) and an excellent cycle performance (reversible capacity of nearly $800 \mathrm{mAh} \mathrm{g}^{1}$ at $0.1 \mathrm{C}$ over 100 cycles) [66]. The average diameter of the nanofiber was $370 \mathrm{~nm}$ and the distance between adjacent nanofibers up to micrometer scale, ensuring enough space for the structure expansion. SEM image characterization revealed the integrity and stabilization of Sn nanofibers over 100 cycles, coincident with the results of galvanostatic (dis) charging tests. Moreover, the unique properties of ultrafine size effects and long-range orientation of the crystalline lattice of 1D nanofiber play an important role in facilitating electrochemical performance. Nearly in the same time, the same team reported the influence of diverse morphologies and crystallographic orientations of Sn on the cycling capability [67]. They prepared the coarse particles or thin layers of Sn by electrochemical deposition. It was found that both electrodes experienced an identical and highly reversible sodiation/desodiation process, i.e., forming b-Sn phase, amorphous $\mathrm{NaSn}$, crystalline $\mathrm{Na}_{9} \mathrm{Sn}_{4}$ and $\mathrm{Na}_{15} \mathrm{Sn}_{4}$ in sequence. Electrochemical characterizations indicated that the thin-layered Sn electrode have a better cycling performance than that of coarse particles.

Nano-architectured electrodes can be able to alleviate mechanical stresses caused by drastic volume fluctuations during sodiation and desodiation. Introducing carbon matrix into Snbased electrodes can further enable high electrochemical performance considering the accessibility of carbon resource and its good conductivity, as well as the characteristics of carbon acting as a buffer or host to ease volume expansion and nanograin aggregation. For instance, the three-dimensional core-shell structured C/ Sn/Ni/TMV1cys (TMV1cys means tobacco mosaic virus (TMV) modified with cysteine) with a nearly vertical alignment of nanorods assembled on metal substrate synthesized on viral scaffolds, showed an initial capacity of $722 \mathrm{mAh} \mathrm{g}^{1}$ along with a retained capacity of $405 \mathrm{mAh} \mathrm{g}^{1}$ after 150 cycles [41]. This prolonged electrochemical cycling was ascribed to the ample space accommodating the vigorous volume changes as well as carbon layer increasing electrical conductivity of electrode material. Furthermore, the anode consisting of Sn thin film deposited on a hierarchical wood fiber substrate was demonstrated to show a stable cycling performance of 400 cycles with an initial capacity of $339 \mathrm{mAh} \mathrm{g}^{1}$ [68]. The soft and mesoporous nature of wood fibers allows to release the mechanical stresses but also serve as an electrolyte reservoir owing to the quick ion transport through the outer and inner surface of fibers. The advantages of small particles and carbon matrix were further demonstrated by 
a special structure of ultra-small $\mathrm{Sn}$ nanoparticles $(\sim 8 \mathrm{~nm})$ embedded in the spherical carbon network (denoted as 8-Sn@C) [69].

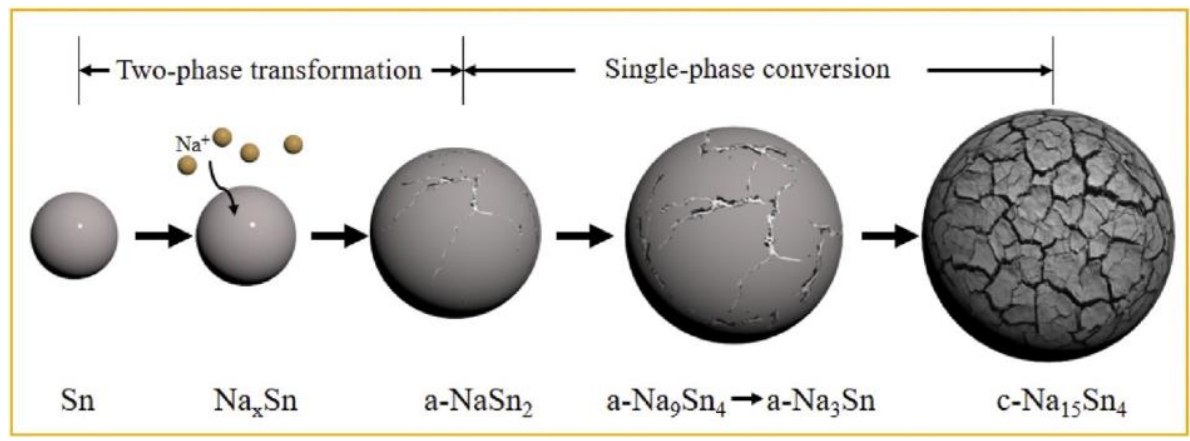

Fig. 5. The structural evolution of Sn sodiation process for SIBs.

The combination of ultra-small nanograins with porous carbon network simultaneously ensure the electrode with an integral electronic conductivity and the capability of enduring intense mechanical constrains upon cycling. Liu et al. proposed a freestanding anode comprised of Sn nanodots encapsulated in porous N-doped carbon nanofibers (denoted as Sn NDs@PNC nanofibers) as a binder and a current collector-free anode [70]. Notably, the Sn NDs@PNC nanofibers delivered a perfect rate capability and cyclic stability, i.e., a capacity of $450 \mathrm{mAh} \mathrm{g}^{1}$ at $10 \mathrm{~A} \mathrm{~g}^{1}$ and $483 \mathrm{mAh} \mathrm{g}^{1}$ over 1300 cycles at $2 \mathrm{~A} \mathrm{~g}^{1}$. In addition to the aforementioned advantages, the homogenous distribution of Sn nanodots in the fibrous carbon matrix would also generate the balanced stress over the whole composite and maintain the integrity of the electrode.

The reduced graphene oxide (rGO) has become another attractive carbonaceous material in virtue of high surface area, which can provide plenty of active sites and the efficient pathways for electron transportation. Very recently, Sn loaded onto rGO and graphene were used as anode for SIBs [71]. This porous framework promises a uniform Sn loading and a sufficient free space for accommodating the volume changes of Sn and promoting good mechanical stability. Thereby a reversible capability of about $500 \mathrm{mAh} \mathrm{g}^{1}$ at $0.5 \mathrm{C}$ and approximate $230 \mathrm{mAh} \mathrm{g}^{1}$ at the high rate of $20 \mathrm{C}$ were achieved.

In addition to two promising methods referred above, the third way intended to advance rate performance and long-term cyclability of Sn-based anode is designing M - Sn intermetallic compound (M is active or inactive metal element for $\mathrm{Na}$ ion storage), which is discussed hereafter in details. Except to the conventional sodiumion batteries, it is very intriguing that a novel dual-ion battery based on sodium-ion electrolyte containing $\mathrm{NaPF}_{6}$ salt, $\mathrm{Sn}$ as the anode and graphite as the cathode was first reported by Sheng et al. [72] During the charging state, $\mathrm{PF}_{6}$ anions intercalate into the graphite cathode while $\mathrm{Na}^{+}$transport onto the $\mathrm{Sn}$ foil anode to form $\mathrm{Na}-\mathrm{Sn}$ alloy simultaneously. Compared with the conventional SIBs, this kind of battery is able to output a much higher working potential as high as $4.8 \mathrm{~V}$.

\subsection{P-based materials}

Among various anode materials in SIBs, phosphorus has the highest theoretical specific capacity of 2596 $\mathrm{mAh} \mathrm{g}^{1}$ and suitable redox potential of around $0.4 \mathrm{~V}$ versus $\mathrm{Na} / \mathrm{Na}^{+}$. According to the crystalline structure, phosphorus can be classified into three allotropes: white, red and black phosphorus. White phosphorus is 
unsuitable for application as anode material because of its high toxicity and reactivity with air. Red P has been studied as anode material for SIBs extensively due to its stability and abundant resources [73] and black $\mathrm{P}$ due to its high electrical conductivity $\left(300 \mathrm{~S} \mathrm{~m}^{1}\right)$ and layered structure. The mechanism of sodiation for both red $\mathrm{P}$ and black $\mathrm{P}$ can be described according to the following equation: $\mathrm{P} / \mathrm{Na}_{\mathrm{x}} \mathrm{P} / \mathrm{Na}_{3} \mathrm{P}(0<\mathrm{x}<3)$ $[74,75]$.

\subsubsection{Red P}

Red phosphorus possesses a chain-like structure (Fig. 6a), which can be viewed as a derivative of $\mathrm{P}_{4}$ wherein one P-P bond is broken but one additional bond is formed with the neighboring tetrahedron. The merits of ultrahigh theoretical capacity and environmental friendliness triggers intensive research on red $\mathrm{P}$ as anode material for SIBs. However, the practical utilization of red P in SIBs is grievously hindered by large volume changes (490\%) and low electronic conductivity $\left(10^{14} \mathrm{~S} \mathrm{~cm}^{1}\right)$ [73]. Furthermore, big volume changes result in pulverization of active materials, causing coverage of surface of active material by thick SEI layer. All these issues have significant influence on electrochemical performance, especially rate capability and cyclability. In this context, several tactics have been employed to address these challenges, including constructing carbonaceous materials and reducing particle size to nanometer scale.

(a)

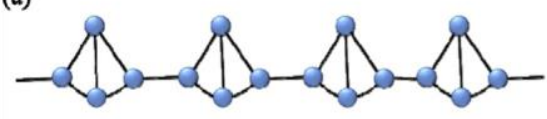

(b)
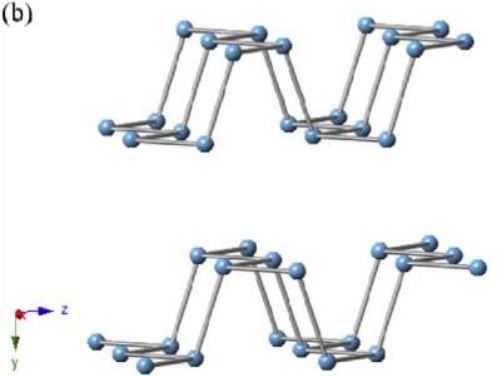

(c)

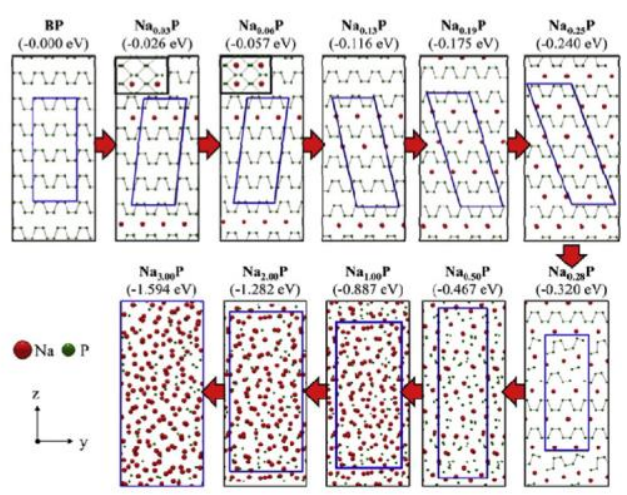

Fig. 6. The crystal structure of red P (a) and black P (b). (c) The schematic diagram of black P sodiation mechanism, in which numbers in parentheses and blue lines represents calculated formation energies of $\mathrm{Na}_{x} \mathrm{P}$ structures and cell sizes of $\mathrm{Na}_{x} \mathrm{P}$ including $64 \mathrm{P}$ atoms adopted. The black insets in $\mathrm{Na}_{0 \$ 03 \mathrm{P}}$ and $\mathrm{Na}_{0 \$ 06 \mathrm{P}}$ represents the view from the top, aiming to clarify position of $\mathrm{Na}$ atoms in the structures [85]. Copyright 2015, American Chemical Society.

Combining red $\mathrm{P}$ with carbon-based materials can effectively increase the electronic conductivity and decrease the mechanical stresses during $\mathrm{Na}$ ions uptake/release process. Recently, various types of carbon materials have been tested for this purpose, including carbon nanotubes [28], carbon black [74,76], graphene $[77,78]$, or mesoporous carbon [78,79]. When uniformly distributed among single-walled carbon nanotubes (denoted as red P-SWCNT) [28], red P-based electrode benefit from an enhanced conductivity and good mechanical properties, resulting in fast-rate capability $\left(\sim 300 \mathrm{mAh} \mathrm{g}^{1}\right.$ at $\left.2000 \mathrm{~mA} \mathrm{~g}{ }^{1}\right)$ and stable long-term cycling ability with only $0.01 \%$ average capacity decay per period over 2000 cycles. Additionally, a large amount of interconnected and continuous pores could promote a tight contact of active material with the 
electrolyte. For example, Li et al. confined amorphous red $\mathrm{P}$ in highly ordered channels of mesoporous carbon matrix CMK-3 (denoted as P@CMK-3) [79]. The Brunauer-Emmett-Teller (BET) showed that specific surface of CMK-3 and P@CMK-3 were 1128.3 and $14.02 \mathrm{~m}^{2} \mathrm{~g}^{1}$, according to the pore volume of 1.41 and $0.06 \mathrm{~cm}^{3} \mathrm{~g}^{1}$, respectively. Taking advantages of aforementioned high specific surface and ordered structure, an impressive rate capability and stable durability of the P@CMK-3 was achieved based on the mass of red $P$.

Graphene is absolutely a rising star as anode materials for SIBs. The reaction kinetics and activity can be largely accelerated due to high electronic conductivity and specific surface area of graphene. The characteristics of brilliant flexibility endow the potential of graphene in wearable electronics applications. For example, red phosphorus nanodots have been densely and uniformly deposited onto reduced graphene oxide sheets (denoted as P@rGO) as anode material for SIBs [78]. The rGO network serves as electron pathway and creates free space for P particles and to accommodate the volume variations. Hence, it was shown that the P@rGO can deliver $914 \mathrm{mAh} \mathrm{g}^{1}$ over 300 cycles at the current density of $1593.9 \mathrm{~mA} \mathrm{~g}^{1}$. Even at an ultrahigh current density of $47818.3 \mathrm{~mA} \mathrm{~g}^{1}$, still high specific capacity of $135.3 \mathrm{mAh} \mathrm{g}^{1}$ was obtained. It is worth noting that an excessive carbon proportion would cause severe specific capacity loss because of the lower specific capacity of carbonaceous materials.

Metal organic frameworks (MOFs) have shown wide application in electrochemical energy storage and catalysts because of its unique structure with well-defined pore size distributions consisting of linked inorganic and organic units [80]. Furthermore, doping heteroatoms like boron, sulfur and nitrogen into the organic section of MOFs could be beneficial to tune the electronic characteristics and surface wettability [81]. Zeolitic imidazole framework-8 (ZIF-8) is one typical MOF containing $\mathrm{Zn}^{+}$and 2-methylimidazolate linkers, in which 2-methylimidazolate contains high content of $\mathrm{N}$ (about 34\%) [82,83]. When the red $\mathrm{P}$ is confined into ZIF-8derived N-doped microporous carbon (denoted as P@N-MPC) [78], the material showed a superior rate capability and cycle life ( $291 \mathrm{mAh} \mathrm{g}^{1}$ at $9 \mathrm{~A} \mathrm{~g}^{1}$ and a tiny capacity decay rate of $0.02 \%$ per cycle at $1 \mathrm{~A} \mathrm{~g}^{1}$ after 1000 cycles with nearly $100 \%$ Coulombic efficiency).

Reducing size into nanometer range is another solution to increase red $\mathrm{P}$ performance for the sake of alleviating the large mechanical strains resulting from huge volume variations. The size effect can not only enhance electrochemical activity of red $\mathrm{P}$, but also shorten diffusion pathway of Nap $[74,76]$. For instance, $\mathrm{P}$ nanoparticles (10e20 nm) deposited onto graphene aerogel (denoted as C@P/GA) by vapor-redistribution strategy presented a superior capacity of $1867 \mathrm{mAh} \mathrm{g}^{1}$ after 100 cycles at $0.1 \mathrm{C}$ and $1095.5 \mathrm{mAh} \mathrm{g}^{1}$ over 200 cycles at $1 \mathrm{C}$ (both based on red P) [77]. The intimate contact between $\mathrm{P}$ and carbon layer as well as the minimized particle size ensure a stable electrode structure and diminish $\mathrm{Na}$ ion diffusion. The graphene in this work, different than the 2D graphene-based materials mentioned above, was integrated from 2D layered structure into 3D porous structure, by which active materials were tightly sealed in the matrix. This creative structure design strongly confirms the bright prospect of red $\mathrm{P}$ as anode materials for SIBs.

\subsubsection{Black $P$}

Among three allotropes of phosphorus, black $\mathrm{P}$ is the most thermodynamically stable and has a layered structure resembling graphite (Fig. 6b). The phosphorene interlayer distance in the case of black $\mathrm{P}$ can be extended up to $3.08 \AA[75,84]$, which is large enough to host $\mathrm{Na}$ ion. The layers are kept together by van der Waals forces [75]. Moreover, black P has an absolutely higher electrical conductivity $\left(\sim 300 \mathrm{~S} \mathrm{~m}^{1}\right)$ than red P 
$\left(10^{12} \mathrm{~S} \mathrm{~m}^{1}\right)[75,84]$. All these properties indicate that black $\mathrm{P}$ can be a promising candidate as anode material for SIBs [85-88]. Hembram et al. first unraveled the sodiation mechanism of black P at atomic level based on DFT [85]. Their work predicates that sodiation process consists of two major consecutive steps: an intercalation process followed by an alloy-type reaction. Fig. $6 \mathrm{c}$ shows the schematic diagram of sodiation mechanism for black P. Both intercalation and alloy-type processes are accompanied with distortion and damage of the laminar structure. Notably, there is no P-P bond breakage and obvious distortion in black P crystal structure when the concentration of intercalated $\mathrm{Na}$ ions is kept under 0.25 per $\mathrm{P}$ atom. Otherwise, $\mathrm{P}-\mathrm{P}$ bond cleavage would begin and the amorphous phase would be formed ultimately. Therefore, it is important to reside in easy diffusion of $\mathrm{Na}$ ions with no phase transition from the layered structure to the amorphous one. Inspired by this intriguing finding, phosphorene/graphene with sandwiched structure [75] and black P/Ketjenblack-multi- walled carbon nanotubes [86] hybrid materials were synthesized and characterized. The hybrid material made out of a few phosphorene layers sandwiched between graphene layers showed a specific capacity of $2440 \mathrm{mAh} \mathrm{g}^{1}$ (based on the mass of $\mathrm{P}$ ) at a current density of $0.05 \mathrm{~A} \mathrm{~g}^{1}$. Nanostructured black phosphorous/Ketjenblack-multi- walled carbon nanotubes composite prepared by high energy ball milling delivered a high specific capacity of 1700 mAh g${ }^{1}$ over 100 cycles at $1.3 \mathrm{~A} \mathrm{~g}^{1}$ and reversible capacity of around $1000 \mathrm{mAh} \mathrm{g}^{1}$ at $3 \mathrm{~A} \mathrm{~g}^{1}$ (both based on the mass of P), displaying a stable cycling performance and high rate capability. In both studies, carbon materials were used as mechanical backbone and electrical highway. These works show different methods of fabrication of carbon-incorporated composites, which could provide some enlightenment for black P as anode for SIBs.

Further application of black $\mathrm{P}$ as anode material in SIBs ought to address the issue of fabricating high quality, large-area, few-layer phosphorene (FL-P) with a small number of defects. Mechanical exfoliation and liquidphase peeling are the most commonly used methods till now [75,87-89]. The FL-P was first reported by one common technique called 'scotch-tape method' [90,91], but chemical residues from scotch tape are inevitably contained. Similarly, liquid-phase exfoliation in organic solvents usually needs a long-time ultrasonic exfoliated process (more than $10 \mathrm{~h}$ ) $[92,93]$ resulting in flake size decline of FL-P (less than a few hundred nanometers) and extensive defects. Consequently, it is highly desirable to find out an effective way for the preparation of largearea phosphorene. With this expectation, a layer-tunable electrochemical cathodic exfoliation method via controlled intercalation rate of tetraalkylammonium cations has been put forward to prepare FL-P [94]. Adopting black P crystals as cathode and a Pt sheet as the counterpart, the insertion of tetraalkylammonium cations into the interlayers of black P begins once applied a constant voltage, following by curling, stripping and peeling of black P. By modulating the applied potentials, phosphorene with various layers (from 2 to 11) could be obtained. The as-prepared phosphorene with 5 layers (denoted as FL-P-5) delivered capacities of $1878.4,1529.9,1108.5,591$, and $321 \mathrm{mAh} \mathrm{g}^{1}$ at the current densities of 100, 250, 500, 1500, and $2500 \mathrm{~mA} \mathrm{~g}^{1}$, respectively, signifying the superior rate capability. Moreover, FL-P-5 displayed a good cycling performance with capacity of $603.3 \mathrm{mAh} \mathrm{g}^{1}$ retained after 100 cycles. This facile electrochemical cathodic exfoliation method to prepare layer-tuned phosphorene would not only facilitate the development of black P-based anode but also pave the way for the exploration of 2D materials as electrode in secondary batteries. However, the initial Coulombic efficiency (less than $40 \%$ ) at the current density of $1500 \mathrm{~mA} \mathrm{~g}^{1}$ was unsatisfactory. This may be ascribed to the formation of thick and insulating SEI layer.

2.3. Reaction mechanism of metallic $\mathrm{Sb}$ and solutions to improve its performance 
$\mathrm{Sb}$ has been considered as a prospective anode material for SIBs due to its relatively high theoretical specific capacity $\left(660 \mathrm{mAh} \mathrm{g}^{1}\right)$ and good electrical conductivity $\left(2.510^{4} \mathrm{~S} \mathrm{~cm}^{1}\right)$ [95,96]. As for the mechanism of $\mathrm{Sb}$ alloying with $\mathrm{Na}$ ions, it is still inconclusive with regard to a very modest literature. In early stage, Sb displayed better electrochemical performance in SIBs than LIBs, which was a striking phenomenon triggering researchers' curiosity. For instance, Darwiche et al. fabricated Na-ion and Li-ion half-cells both adopting commercialized $\mathrm{Sb}$ as electrode, with the purpose to establish the working mechanisms [27]. Through relevant electrochemistry analysis, they proposed that Sb would undergo a complicated alloying reaction in SIBs compared with LIBs. The reaction mechanism in the case of LIB could be simply described as follows: $\mathrm{Sb}$ p $5 \mathrm{Lip} 4 \mathrm{Li}_{2} \mathrm{Sb}_{4} \mathrm{Li}_{3} \mathrm{Sb}$. In the case of SIB, the intermediate phases are mostly amorphous and have not been identified, though the formation of final sodiated product $\mathrm{Na}_{3} \mathrm{Sb}$ can be evidenced. Darwiche et al. [27] ascribed the better performances of $\mathrm{Na} / \mathrm{Sb}$ to a decreased volume expansion upon going from $\mathrm{Sb}\left(181.1 \AA^{3}\right)$ to hexagonal $\mathrm{Na} 3 \mathrm{Sb}$ $\left(237 \AA^{3}\right.$ ) relative to $\mathrm{Li}_{3} \mathrm{Sb}\left(283.8 \AA^{3}\right)$. Afterwards, Baggetto et al. [97] pointed out to some differences between the first cycle and the subsequent cycles, residing in that $\mathrm{Sb}$ and $\mathrm{Na}$ ions would proceed through a different pathway associated with formation of amorphous $\mathrm{Na}_{\mathrm{x}} \mathrm{Sb}$ phases. They further ascribed a better performance of $\mathrm{Sb}$ with $\mathrm{Na}$ ions than Li ions (given previously by Darwiche et al. [27]) to the absence of formula unit (Z) in the unit cells (Z 1/4 2 and 4 for $\mathrm{Na}_{3} \mathrm{Sb}$ and $\mathrm{Li}_{3} \mathrm{Sb}$, respectively). The corrected volume changes to form $\mathrm{Na}_{3} \mathrm{Sb}$ and $\mathrm{Li}_{3} \mathrm{Sb}$ should be around $293 \%$ and $135 \%$, respectively. Thus, Baggetto et al. [97] proposed that reduced anisotropic mechanical stresses derived from the predominant formation of amorphous intermediates (except of only one crystalline product of $\mathrm{Na}_{3} \mathrm{Sb}$ contrary to three $\mathrm{Sb} / \mathrm{Li}$ crystalline phases in LIBs) might be the exact reason of the better performance of $\mathrm{Sb}$ in SIBs than LIBs. The amorphous $\mathrm{Na}_{3-\mathrm{x}} \mathrm{Sb}$ (x z 0.4e0.5) and $\mathrm{Na}_{1 \$ 7} \mathrm{Sb}$ have been detected very recently [98]. Thus, the latest $\mathrm{Sb} / \mathrm{Na}$ alloying mechanism could be summarized as following:

$$
\begin{array}{rr}
2 S b \stackrel{+(6-x) N a}{\longrightarrow} N a_{3-x} S b+N a_{3} S b \stackrel{+x N a}{\longrightarrow} 2 N a_{3} S b & \text { first sodiation } \\
N a_{3} S b \stackrel{-1.3 N a}{\longrightarrow} N a_{1.7} S b \stackrel{-0.7 N a}{\longrightarrow} N a_{1.0} S b & \text { first desodiation } \\
N a_{1.0} S b+S b \stackrel{+0.7 N a}{\longrightarrow} N a_{1.7} S b+S b \stackrel{+(3-x) N a}{\longrightarrow} N a_{1.7} S b+ \\
N a_{3-x} S b \stackrel{+(1.3-x) N a}{\longrightarrow} 2 N a_{3-x} S b \stackrel{+2 x N a}{\longrightarrow} 2 N a_{3} S b & \text { second sodiation }
\end{array}
$$

Similar to most of other alloying-based materials, the cycling process of Sb anode for SIBs was unavoidably accompanied by large volume expansion ( 400\%), leading to a serious degradation of electrode, loss of contact between active materials and current collector as well as poor cycle life [99]. These factors strongly hinder the application of $\mathrm{Sb}$ as anode for SIBs.

Designing nanostructured electrodes is always a common but viable solution to address the issues of abrupt capacity decay and electrical contact loss arising from volume expansion and contraction. The enhanced electrochemical performance can be likely achieved by nanoscale particles in the light of shortened ion or electron transport pathways and strengthened ability to endure absolute stress. Carbon materials are always considered as a preferential choice to accommodate the significant volume changes and facilitate the ionic diffusion. Benefiting from the dispersing, conducting and buffering effects originated from interconnected 
carbon nanofiber networks (denoted as ICNNs), the composite Sb nanoparticles anchored on ICNNs delivered a stable cycling performance $\left(542.5 \mathrm{mAh} \mathrm{g}^{1}\right.$ with a capacity substation of $96.7 \%$ over 100 cycles at $100 \mathrm{~mA}$ $\mathrm{g}^{1}$ ) and great rate capability (reversible capacity of $325 \mathrm{mAh} \mathrm{g}^{1}$ at $3200 \mathrm{~mA} \mathrm{~g}^{1}$ ) [95]. The good effects originated from ICNNs are vividly depicted in Fig. 7. Similarly, pitaya-like Sb@C prepared by aerosol spray drying synthesis also showed an enhanced electrochemical performance [100]. Na storage capacity of 655 $\mathrm{mAh} \mathrm{g}^{1}$ (very near to theoretical capacity of $\mathrm{Sb}$ ) at $\mathrm{C} / 15$ over 100 cycles and around $400 \mathrm{mAh} \mathrm{g}^{1}$ at $3 \mathrm{C}$ were obtained. Tight contact of $\mathrm{Sb}$ with carbon buffer is supposed to be responsible for this superior electrochemical performance.

The composites of Sb/N-doped carbon [101,102], Sb/rGO [103,104], and Sb/porous carbon [105,106] were all reported to possess the enhanced electrochemical performance including rate capability and cycling durability. Noticeably, N-doped carbon was assigned to offer more defects and active sites without the lattice mismatch, leading to the improved electrochemical performance [107,108]. In order to advance the developments of $\mathrm{Sb}$ as anode for SIBs, Gu et al. came up with an innovative idea to fabricate Sb nanosheets considering the metallic Sb with gray allotrope (R3m space group) as a graphite-like 2D layered material [109]. It adopts a layered structure in which layers consist of fused, ruffled, sixmembered rings and the nearest and next-nearest neighbors form an irregular octahedral complex, with the three atoms in each double layer slightly closer than the three atoms in the next, leading to a high density of $6.697 \mathrm{~g} \mathrm{~cm}^{3}$. The bonding interactions between layers are van der Waals forces, which make it possible to prepare Sb nanosheets. Herein, this team proposed a synthesis of composite Sb nanosheets and graphene (denoted as SbNS-G) via the liquidphase exfoliation method. In this hybrid film, the notorious volume changes were alleviated by flexible graphene and ionic and electrical diffusion were enhanced by layered structure. Therefore, SbNS-G film delivered high reversible volumetric capacities of 525 and $417 \mathrm{mAh} \mathrm{cm}$ at the relatively high current densities of 0.4 and $0.8 \mathrm{~mA} \mathrm{~cm}{ }^{2}$, respectively. Even at the ultrahigh current density of $4 \mathrm{~mA} \mathrm{~cm}^{2}$, still the high capacity of more than $200 \mathrm{mAh} \mathrm{cm} \mathrm{c}^{3}$ over 100 cycles was retained, demonstrating the high-rate capability and good cyclic performance. This novel design may provide metallic $\mathrm{Sb}$ as anode material for a broader application in SIBs.

\section{4. $\mathrm{M}-\mathrm{Sn} / \mathrm{P} / \mathrm{Sb}$ compounds}

Engineering binary alloys has turned out to be an effective way to enhance the electrochemical properties of sodium-ion batteries. With respect to $\mathrm{M}-\mathrm{Sn} / \mathrm{P} / \mathrm{Sb}$ compounds, $\mathrm{M}$ represents an electrochemically active or inactive component. Inactive $\mathrm{M}$ could be used as a cushion to alleviate the volume changes during sodiation/desodiation. These alloys also possess a relatively high specific capacity ( $\mathrm{SnSe}_{2} 756 \mathrm{mAh} \mathrm{g}^{1}, \mathrm{FeP}$ $924 \mathrm{mAh} \mathrm{g}^{1}, \mathrm{Cu}_{3} \mathrm{P} 366 \mathrm{mAh} \mathrm{g}^{1}, \mathrm{Se}_{4} \mathrm{P}_{4} 1218 \mathrm{mAh} \mathrm{g}^{1}$ ) [26,45,47,110]. When $\mathrm{M}$ is an active element, the reaction mechanism usually consists of 

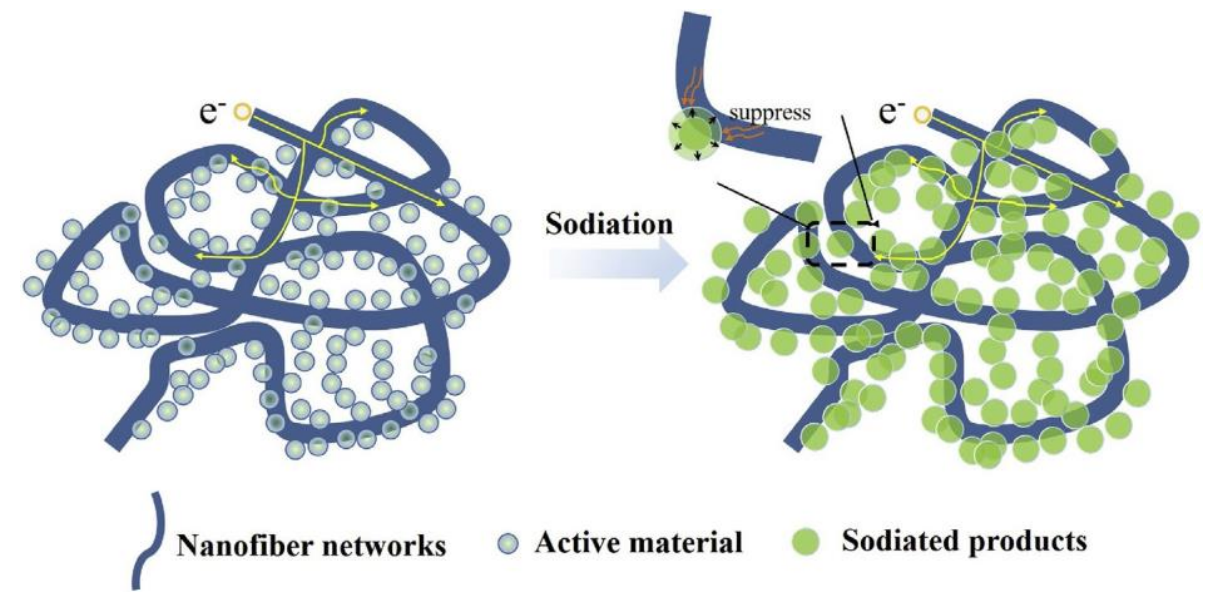

Active material

Sodiated products

Fig. 7. The schematic illustration of advantages (fast electron diffusion tunnels and alleviating the huge volume change) originated from interconnected carbon nanofiber networks.

conversion reaction and alloying reaction. When $\mathrm{M}$ is an inactive element, the reaction mechanism is (take FeP [26] as an example):

$$
\begin{aligned}
& \mathrm{FeP}+3 \mathrm{Na}^{+}+3 \mathrm{e}^{-} \rightarrow \mathrm{Na}_{3} \mathrm{P}+\mathrm{Fe} \quad \text { (discharging) } \\
& \mathrm{Na}_{3} \mathrm{P}+\mathrm{Fe} \rightarrow \mathrm{P}+\mathrm{Fe}+3 \mathrm{Na}^{+}+3 \mathrm{e}^{-} \quad \text { (charging) }
\end{aligned}
$$

\subsubsection{Active $\mathrm{M}-\mathrm{Sn} / \mathrm{P} / \mathrm{Sb}$ intermetallic compounds}

Active $\mathrm{M}$ includes $\mathrm{Sn}, \mathrm{P}, \mathrm{Sb}$, or $\mathrm{Se}$. For instance, $\mathrm{SnSe}_{2}$ attracts attention because of its relatively high theoretical specific capacity of $756 \mathrm{mAh} \mathrm{g}^{1}$ and 2D layered structure. Moreover, the interlayer spaces are loosely bounded by van der Waals bonds. $\mathrm{SnSe}_{2}$ nanosheets and $\mathrm{SnSe}_{2} / \mathrm{rGO}$ nanocomposites were first reported to be prepared by facile hydrothermal method [110]. Na ion insertion would undergo according to three consecutive steps: first insertion of $\mathrm{Na}$ ions, then conversion reaction followed by alloying reaction, presented hereafter respectively:

$$
\begin{aligned}
& \mathrm{xNa}^{+}+\mathrm{SnSe}_{2}+\mathrm{xe}^{-} \rightarrow \mathrm{Na}_{\mathrm{x}} \mathrm{SnSe}_{2} \\
& 4 \mathrm{Na}^{+}+\mathrm{SnSe}_{2}+4 \mathrm{e}^{-} \rightarrow 2 \mathrm{Na}_{2} \mathrm{Se}+\mathrm{Sn} \\
& \mathrm{Sn}+3.75 \mathrm{Na}^{+}+3.75 \mathrm{e}^{-} \rightarrow \mathrm{Na}_{3.75} \mathrm{Sn}
\end{aligned}
$$

The coexisting Se- and Sn-rich phases generated during sequential reactions could self-support one another. Simultaneously, this hybrid material was featured with large specific surface area $\left(87.0 \mathrm{~m}^{2} \mathrm{~g}^{1}\right)$ and high electrical conductivity $\left(2.1210^{1} \mathrm{~S} \mathrm{~cm}^{1}\right)$. As a result, $\mathrm{SnSe} 2 / \mathrm{rGO}$ exhibited $365 \mathrm{mAh} \mathrm{g}^{1}$ at $2.0 \mathrm{~A} \mathrm{~g}^{1}$ and maintained $515 \mathrm{mAh} \mathrm{g}^{1}$ over 100 cycles at $0.1 \mathrm{~A}$, indicating good rate capability and cycling performance. PSe alloy was also reported as a valuable anode material for SIBs. Lu et al. fabricated $\mathrm{Se}_{4} \mathrm{P}_{4}$ by a simple ball milling method [45]. Se on the one hand acts as $\mathrm{Na}$ ion storage container and contributes to a part of capacity, on the other hand improves the whole electrode conductivity with regard to insulating $\mathrm{P}$ ( 9 orders of magnitude higher conductivity than that of P). Due to the intrinsic good conductivity and high theoretical 
capacity (1217 mAh g${ }^{1}$ ), it was shown that $\mathrm{Se}_{4} \mathrm{P}_{4}$ manifests high reversible capacity (1048 $\mathrm{mAh} \mathrm{g}^{1}$ at $50 \mathrm{~mA}$ $\mathrm{g}^{1}$ ), good cycling durability ( $804 \mathrm{mAh} \mathrm{g}^{1}$ after 60 cycles), and excellent rate capability ( $332 \mathrm{mAh} \mathrm{g}^{1}$ at 3000 $\mathrm{mA} \mathrm{g}^{1}$ ). Furthermore, it was confirmed that discharge capacity could be up to $985 \mathrm{mAh} \mathrm{g}^{1}$ based on the mass of $\mathrm{Se}_{4} \mathrm{P}_{4}$ with an average output potential of about $2.5 \mathrm{~V}$ in the full battery employing $\mathrm{Se}_{4} \mathrm{P}_{4}$ as anode and $\mathrm{Na}_{3}\left(\mathrm{VO}_{0.5}\right)_{2}\left(\mathrm{PO}_{4}\right)_{2} \mathrm{~F}_{2} / \mathrm{C}$ as cathode.

The theoretical capacity of $\mathrm{SnSb}$ for SIBs is $752 \mathrm{mAh} \mathrm{g}^{1}$ with alloying/dealloying reactions of $\mathrm{Sn}$ and $\mathrm{Sb}$ occurring at different potentials, which could buffer the absolute stresses reciprocally during cycling to a certain extent. Benefiting from these particular properties, $\mathrm{SnSb}$ deliveries high reversible capacity of about $550 \mathrm{mAh}$ $\mathrm{g}^{1}, 430 \mathrm{mAh} \mathrm{g}{ }^{1}$, and $390 \mathrm{mAh} \mathrm{g}^{1}$ over 100 cycles at $200 \mathrm{~mA} \mathrm{~g}^{1}$,

$1000 \mathrm{~mA} \mathrm{~g}^{1}$, and $5000 \mathrm{~mA} \mathrm{~g}^{1}$, respectively [111]. Additionally, other similar types of materials such as $\mathrm{Sn}_{5} \mathrm{SbP}_{3}$ [112], $\mathrm{Sn}_{4} \mathrm{P}_{3}$ [113], and SnBi-Sb alloy [114] have been studying as anodes for SIBs.

\subsubsection{Inactive $\mathrm{M}-\mathrm{Sn} / \mathrm{P} / \mathrm{Sb}$ compounds}

Inactive $\mathrm{M}$ could not only act as an electrochemically inactive cushion to relieve severe stresses but also play a role in improving electrical conductivity of the whole electrode. Numerous inactive $\mathrm{M}-\mathrm{Sn}(\mathrm{M} 1 / 4 \mathrm{Cu}, \mathrm{Co}, \mathrm{Ni})$ [41,56,115], M Sb (M 1/4 Cu, Zn) [116,117], M P (M 1/4 Co, Fe) [26,118] alloys have been investigated as anode for SIBs. One of examples for promising SIBs is FeP, where $\mathrm{Fe}$ is a conductive matrix and alleviates the volume fluctuation and $\mathrm{P}$ possesses a high theoretical specific capacity. In sodiation process, $\mathrm{FeP}$ would transform to $\mathrm{Fe}$ and $\mathrm{Na}_{3} \mathrm{P}$ finally [26]. However, their active materials would aggregate and pulverize during cycling because of uneven distribution of particle size from nanoscale to microscale. The capacity decreased from initial 764.7 mAh $\mathrm{g}^{1}$ to $220 \mathrm{mAh} \mathrm{g}^{1}$ after 40 cycles with the capacity loss of $71 \%$. Lim et al. prepared core-shell structured $\mathrm{CoP} / \mathrm{FeP} / \mathrm{rGO}$ composite [119]. Abundant pores could not only endure large volume change, but also reduce $\mathrm{Na}$ ion diffusion paths. This hybrid material achieved outstanding rate capability and cycling performance in which a specific capacity of 480.2, 435.1, 403.3, 374.6 and $341.2 \mathrm{mAh} \mathrm{g}^{1}$ can be maintained at current density of $0.1,0.2,0.5,1$ and $2 \mathrm{~A} \mathrm{~g}^{1}$ respectively, and $456.2 \mathrm{mAh} \mathrm{g}^{1}$ over 200 cycles at $100 \mathrm{~mA} \mathrm{~g}^{1}$, inspiring the future effective strategies of alloy- and conversionbased electrode engineering for SIBs.

Constructing nanorod arrays began to show its bight future since Cui group [120] fabricated silicon nanowires as the anode for LIBs. This architecture is with several merits, which is shown in Fig. 8. First, the arrayed texture allows for the accommodation of strain along a specific orientation during (dis)charging processes, being conductive to long-term cycling stability. Besides, the morphology with orientated direction (e.g., nanowires, nanotubes, etc.) shortens ion or electron diffusion distance, accompanied with enhanced electronic conductivity therefore better rate capability. Furthermore, the interval space between arrays allow for the full

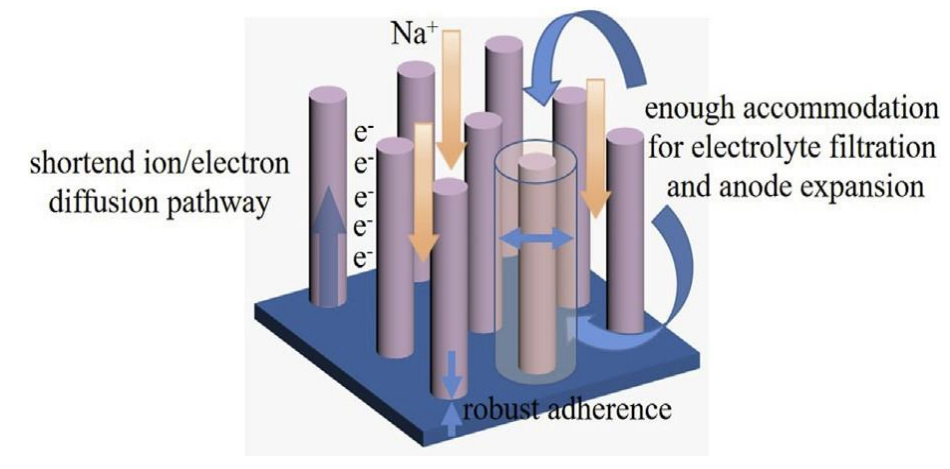


Fig. 8. Schematic representation of prominent features of nanoarrays.

infiltration of the electrolyte, promoting the utilization of active materials. In addition, binder-free electrodes avoid the combination of some additives including conductive carbon and polymer binders, which bring in some undesirable additional interfaces, responsible for the capacity loss to a certain extent. Based on this tactic, $\mathrm{Cu}_{3} \mathrm{P}$ nanowire anode exhibited a stable cycling performance in SIBs (an average of $0.12 \%$ capacity drop per cycle at $1 \mathrm{~A} \mathrm{~g}^{1}$ in 260 cycles) [47].

\section{Typical conversion-based materials (metal oxides and metal sulfides)}

\subsection{Metal oxides}

Metal oxides $\left(\mathrm{MO}_{\mathrm{x}}\right)$ have high theoretical reversible capacity ( $>600 \mathrm{mAh}^{1}$ ) due to polyelectron reactivity. The reaction mechanisms of $\mathrm{MO}_{\mathrm{x}}$ can be classified into two types: $\mathrm{M}$ being nonelectrochemical active elements, such as $\mathrm{Fe}, \mathrm{Co}, \mathrm{Ni}$ and $\mathrm{Cu}$ and $\mathrm{M}$ being electrochemical active elements, such as $\mathrm{Sn}$ and $\mathrm{Sb}$. Metal element and sodium oxide could form in the former case. This process can be expressed as follow:

$$
\mathrm{MO}_{\mathrm{x}}+2 \mathrm{xNa}^{+}+2 \mathrm{xe}^{-} \leftrightarrow \mathrm{xNa}_{2} \mathrm{O}+\mathrm{M}
$$

For the latter case, a conversion reaction occurs first (according to reaction 9), then followed by alloying reaction, which can be described as below:

$$
\begin{aligned}
& \mathrm{MO}_{\mathrm{x}}+2 \mathrm{xNa}^{+}+2 \mathrm{xe}^{-} \leftrightarrow \mathrm{xNa}_{2} \mathrm{O}+\mathrm{M} \\
& \mathrm{xNa} 2 \mathrm{O}+\mathrm{M}+\mathrm{yNa}^{+}+\mathrm{ye}^{-} \leftrightarrow \mathrm{xNa}_{2} \mathrm{O}+\mathrm{Na}_{\mathrm{y}} \mathrm{M}
\end{aligned}
$$

Though theoretically metal oxides with conversion reactions have high specific capacity, the experimental capacity is relatively low because of intrinsic poor conductivity and huge volume expansion. Notably the initial Coulombic efficiency is usually below $70 \%$. This may be attributed to degradation of electrolytes and formation of SEI layer [121-124]. To restrict the volume change, the design of nano-crystallized and nanostructured electrode materials are common pathways to improve electrochemical performance.

Among various metallic oxides based on conversion reactions, Sn-based oxides attracted the most interests owing to its relatively high theoretical reversible capacity (1378 $\left.\mathrm{mAh} \mathrm{g}^{1}\right)$, low cost, abundance, simple synthesis and enhanced safety [125-127]. The main problem of $\mathrm{SnO}_{2}$ is the extremely large volume change (about 520\%) in the process of alloying from Sn to $\mathrm{Na}_{15} \mathrm{Sn}_{4}$ [125-127], as well as the aggregation of Sn particles during cycling [128]. In order to solve these issues, several efforts have been devoted to modify $\mathrm{SnO}_{2}$, including utilization of novel morphology [129] and introducing of carbon based materials [51,130,131]. For example, carbon cloth and graphene decorated $\mathrm{SnO}_{2}$ were prepared with the aim of improving electrochemical performance $[51,130,131]$. Correspondingly, is was shown that these materials exhibited the reversible specific capacity of $501 \mathrm{mAh} \mathrm{g}^{1}$ at $0.14 \mathrm{~A} \mathrm{~g}^{1}, 448 \mathrm{mAh} \mathrm{g}^{1}$ at $0.05 \mathrm{~A} \mathrm{~g}^{1}$ and $306 \mathrm{mAh} \mathrm{g}^{1}$ at $0.1 \mathrm{~A} \mathrm{~g}^{1}$, respectively. Compared with pristine $\mathrm{SnO}_{2}$, the composite of $\mathrm{SnO}_{2}$ and carbon based materials, especially for graphene (Fig. 9), has shown the enhanced electrochemical performance, no matter in reversible capacity or rate capability. It may be attributed to the graphene virtues of extraordinary electrical behavior, chemical stability and high specific surface area $\left(2630 \mathrm{~m}^{2} \mathrm{~g}^{1}\right)$. For instance, it was demonstrated that $2 \mathrm{D}$ graphene sheet could limit the expansion 
and shrinkage of $\mathrm{SnO}_{2}$ particles [132], which is showed in Fig. 9. Furthermore, $\mathrm{SnO}_{2} / \mathrm{N}$-doped graphene composite even performed better than $\mathrm{SnO}_{2} /$ bare graphene composite [133]. The analysis showed that the enhanced performance originated from presence of more electroactive sites caused by N-doping. The N-doping had an influence on the improved reversible specific capacity mainly stemmed from the increased electron transfer efficiency. More interestingly, Fan et al. found that amorphous $\mathrm{SnO}_{2}$ exhibited greater electrochemical performance than crystalline $\mathrm{SnO}_{2}$ due to the better endurance for volume changes of amorphous state than crystalline oxides. Based on this conclusion, they designed the analogous experiments to study the influence of $\mathrm{SnO}_{2}$ crystallinity on its electrochemical performance [134]. The amorphous $\mathrm{SnO}_{2}$ exhibited the reversible specific capacity of $380.2 \mathrm{mAh} \mathrm{g}^{1}$ at the current density of $50 \mathrm{~mA} \mathrm{~g}^{1}$ over 100 cycles, but crystalline $\mathrm{SnO}_{2}$ just delivered one third of the capacity delivered by amorphous $\mathrm{SnO}_{2}$ under the same testing conditions. The superior electrochemical performance of amorphous $\mathrm{SnO}_{2}$ mainly benefited from the intrinsic isotropic properties, the improved $\mathrm{Nap}$ ion diffusion coefficient and the strong interaction between amorphous $\mathrm{SnO}_{2}$ and graphene. Furthermore, smaller amorphous $\mathrm{SnO}_{2}$ particles could better release the larger volume strains.

\subsection{Metal sulfides}

Metal sulfides can be divided into two types of structures: layered and non-layered structure. Most metal sulfides $\left(\mathrm{SnS}_{2}, \mathrm{MoS}_{2}, \mathrm{WS}_{2}, \mathrm{TiS}_{2}\right)$ have distinctive layered structure, wherein atoms are stably retained with covalent bonds but the layers are connected by weak van der Waals forces. Consequently, some polar molecules are capable to enter between the layers through adsorption, intercalation and suspension without structure damage. Researchers have demonstrated that these materials could show superior electrochemical performance.

As a typical layered material, $\mathrm{MoS}_{2}$ has been widely explored as anode for SIBs. During sodiation process, $\mathrm{MoS}_{2}$ undergoes two-step reactions: Nap intercalation in which exists a two-phase reaction from trigonal prismatic $2 \mathrm{H}-\mathrm{MoS}_{2}$ to octahedral $1 \mathrm{~T}-\mathrm{NaMoS}_{2}[131,135]$ and conversion reaction. During intercalation, once more than $1.5 \mathrm{Na}$ ions per formula of $\mathrm{MoS}_{2}$ are intercalated, the structure

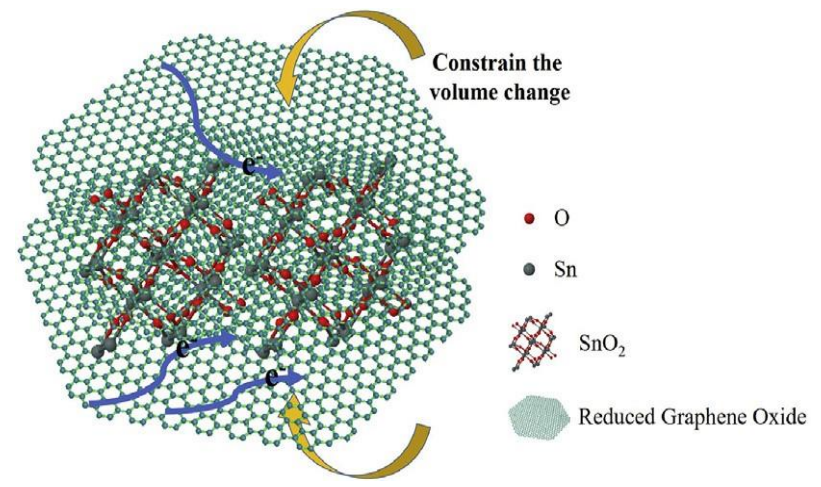

Fig. 9. The schematic diagram of $\mathrm{SnO}_{2}$ embraced by rGO sheets.

of $\mathrm{NaMoS}_{2}$ is not preserved and then conversion reaction begins. Moreover, $1 \mathrm{~T}-\mathrm{NaMoS}$ has certain amounts of defects and the size of series superstructure domains is $3 \mathrm{e} 5 \mathrm{~nm}[131,135]$. Recently, MoS 2 nanosheet (thickness around $4 \mathrm{~nm}$ ) embedded in carbon nanowires was reported for the first time [136]. The ultra-small 
particle size could shorten the diffusion distance and promote the occurrence of electrochemical reactions. As-prepared $\mathrm{MoS}_{2}$ nanosheet delivered the reversible capacity of 854, 484, and $253 \mathrm{mAh} \mathrm{g}{ }^{1}$ over 100 cycles at the current densities of $0.1,1$, and $10 \mathrm{~A} \mathrm{~g}^{1}$, respectively. Similarly, few-layer $\mathrm{MoS}_{2}$ nanoplate with the thickness of about $10 \mathrm{~nm}$ was fabricated through ultrasonic exfoliation technique [137]. Fig. 10 shows a large distance of $6.38 \AA$ between (002) crystal faces, explaining a reason of good cycling stability (386 mAh g 1 over 100 cycles) and rate capability of $\mathrm{MoS}_{2}$ nanosheets $\left(500,450,420\right.$ and $300 \mathrm{mAh} \mathrm{g}{ }^{1}$ at 40, 80, 160 and $320 \mathrm{~mA} \mathrm{~g}^{1}$, respectively). Enlarged interlayer distances would be beneficial in accommodation of more $\mathrm{Na}$ ions per unit volume, thereby the enhanced rate capability. The analysed results demonstrate this prospective and the great potential of $\mathrm{MoS}_{2}$ nanosheets as anode for SIBs. Graphene characterized by good electron conductivity and high specific surface area was introduced to $\mathrm{MoS}_{2}$ in order to further improve the electrochemical performance of $\mathrm{MoS}_{2}[48,138,139]$. 3D MoS 2 -graphene microspheres composed of multiple nanospheres delivered the reversible specific capacity of $323 \mathrm{mAh} \mathrm{g}^{1}$ at $1.5 \mathrm{~A} \mathrm{~g}^{1}$ over 600 cycles with Columbic efficiency of $99.98 \%$ [138]. DFT calculation revealed the intended absorption of Na ions on $\mathrm{MoS}_{2}$ in the $\mathrm{MoS}_{2} / \mathrm{RGO}$ heterostructure rather than intercalation into $\mathrm{MoS}_{2} / \mathrm{RGO}$ hetero-interface [139]. Furthermore, DFT results also approved that heterointerface could significantly improve the conductivity of $\mathrm{MoS}_{2}$ and simultaneously ensure better diffusion mobility of $\mathrm{Na}$ ions on the $\mathrm{MoS}_{2}$ surface and increased electron transfer from Nap to $\mathrm{MoS}_{2}$. These findings can be useful in the development of new research directions concerning $\mathrm{MoS}_{2}$ as anode material for SIBs. Notably, Zhu et al. [140] designed a sodium-ion based dual-ion battery taking penne-like $\mathrm{MoS}_{2} /$ carbon nanocomposite as the anode. It delivered a reversible capacity of $65 \mathrm{mAh} \mathrm{g}^{1}$ at $200 \mathrm{~mA} \mathrm{~g}^{1}$ in the potential window of $1.0 \mathrm{e} 4.0 \mathrm{~V}$ (in this potential range only Nap intercalation reaction exists for $\mathrm{MoS}_{2}$ ).
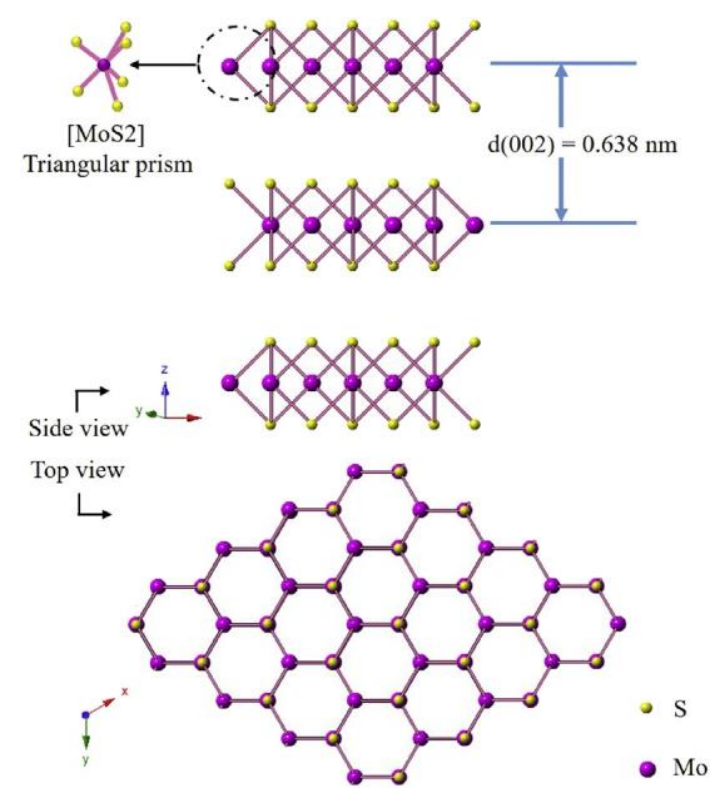

Fig.10. The refined structural model of the exfoliated $\mathrm{MoS}_{2}$ viewed along the [110] and [001] directions. 
$\mathrm{WS}_{2}$ is an emerging anode material for SIBs. The layered $\mathrm{WS}_{2}$ incorporated by reduced graphene oxide showed the reversible capacity of $334 \mathrm{mAh} \mathrm{g}^{1}$ at a current density of $200 \mathrm{~mA} \mathrm{~g}{ }^{1}$ over 200 cycles [141]. WS nanowires with the diameter of around $25 \mathrm{~nm}$ could perform the long cycle life (up to 1400 cycles) in the potential window between 0.5 and $3 \mathrm{~V}$. Morphology modification is an usual way to achieve long-term cycle life and fast rate performance for $\mathrm{WS}_{2}$ [142-145]. In addition, some non-layered metal sulfides were also demonstrated to have interesting sodiation/desodiation properties, such as $\mathrm{FeS}_{2}$ [146], $\mathrm{Sb}_{2} \mathrm{~S}_{3}$ [147], $\mathrm{NiS}_{2}$ [148], and $\mathrm{Cog}_{9} \mathrm{~S}_{8}$ [149]. Compared with layered metal sulfides, it is difficult to tune the interlayer distance of nonlayered metal sulfides, which are restricted by their intrinsic properties. In general, non-layered metal sulfides show worse cycle life performance. Modification of electrolyte composition and adding for example $\mathrm{NaSO}_{3} \mathrm{CF}_{3}$ solvent into the ether electrolyte were demonstrated to be helpful to enhance the cycle performance of sulfides [50]. Noticeably, it has been found that $\mathrm{FeS}_{2}$ would suffer from a fast capacity decay and poor cycling performance when the cut-off voltage is below $0.8 \mathrm{~V}$ [146]. It showed a better cycling performance and higher energy density when the cut-off potential is above $0.8 \mathrm{~V}$. This phenomenon may be attributed to the severe structure destruction occurred below $0.8 \mathrm{~V}$ and demonstrates the significance of voltage to the energy density. The strategy of decorating with bifunctional carbon has been adopted as an efficient way to buffer the volume expansion and to improve the electronic conductivity of SIBs. By applying this strategy, $\mathrm{NiS}_{2} @ \mathrm{C} @ \mathrm{C}$ prepared by Zhao et al. delivered $448 \mathrm{mAh} \mathrm{g}^{1}$ at $1.6 \mathrm{~A} \mathrm{~g}^{1}$ with the initial Coulombic efficiency of 79.65\% [150].

Notably, Ge et al. systematically studied the influence of $\mathrm{O}, \mathrm{S}, \mathrm{Se}$ to the $\mathrm{Co}_{3} \mathrm{X}_{4}\left(\mathrm{X} \frac{1 / 4}{\mathrm{O}}, \mathrm{S}, \mathrm{Se}\right)$ from the prospective of electronic structure, morphology and electrochemical properties [151]. DFT studies suggested that with the reduction of band gap $\left(\mathrm{Co}_{3} \mathrm{O}_{4}>\mathrm{Co}_{3} \mathrm{~S}_{4}>\mathrm{Co}_{3} \mathrm{Se}_{4}\right)$, the lattice, bond length and coordination number would increase, thereby facilitate the electron transfer. The electrochemical test showed that Na-storage capability was enhanced in the sequence of $\mathrm{Co}_{3} \mathrm{O}_{4}, \mathrm{Co}_{3} \mathrm{~S}_{4}$ and $\mathrm{Co}_{3} \mathrm{Se}_{4}$, confirming the DFT results. In addition, it was also found that the lower the binding energy of $\mathrm{Na}_{2} \mathrm{X}\left(\mathrm{Na}_{2} \mathrm{O}>\mathrm{Na}_{2} \mathrm{~S}>\mathrm{Na}_{2} \mathrm{Se}\right)$, the stronger the surfacedominated redox behaviors. Some novel binary metal oxides also attract some researchers' attention. For example, the $\mathrm{N}$-rich carbon coated $\mathrm{CoSnO}_{3}$ derived from Co-MOF with enhanced sodium storage performance [148] was reported recently. In this work, $\mathrm{CoSnO}_{3} \mathrm{MOFs}$ was successfully synthesized through the chemical bonding between $\mathrm{Co}^{+}$and 2-methylimidazole, providing a new method to prepare binary metal oxides.

The pseudo capacitive behavior is often discovered in conversion based materials, especially in metal oxides and sulfides. The pseudo capacitance comes from a reversible electrochemical reaction occurring on or near the surface of electrode materials [152]. These redox reactions are only related to the charge transfer but without the cleavage and formation of the chemical bonds. Herein, it sheds the great light for the materials with pseudo capacitance to deliver high energy density at high charge-discharge rates. In particular, pseudo capacitance can be classified into two types, intrinsic ones and extrinsic ones [153]. Intrinsic ones refer to the materials which could always exhibit pseudo capacitance regardless of the particle sizes and morphologies (e.g., $\mathrm{RuO}_{2}$ and $\mathrm{Nb}_{2} \mathrm{O}_{5}$ ), whereas only extrinsic ones (e.g., $\mathrm{V}_{2} \mathrm{O}_{5}$ ) are made into nanoscale can they achieve pseudo capacitance [152,154-156]. Currently, it is only known that the crystal structure determines the intrinsic pseudo-capacitance nature, but the further mechanism is not clear yet. There is still a long way to go to explore the concrete inherence of it. As for extrinsic materials, the pseudo-capacitive contribution is greatly related to the specific surface area (i.e., active sites). For example, it has been demonstrated that the pseudo capacitance can be tunable for $\mathrm{SnS}$ by changing its 
morphologies [157]. At $0.8 \mathrm{mV} \mathrm{s}^{1}$, the pseudo capacitive contribution was $84 \%$ for the nano-honeycomb $\mathrm{SnS}$, but $81 \%$ for the nano-flake SnS and only around $60 \%$ for the nano-wall SnS. The pseudo capacitance also followed this trend at other scan rates. This phenomenon is in accordance with the sequence of specific surface are from the largest to the least. Analogously, nanosized $\mathrm{Fe}_{1-\mathrm{x}} \mathrm{S}$ [158] and $\mathrm{MnO}_{2}$ [159] have also been found to have the pseudo capacitive effect. Though some achievements have been obtained in exploring the capacitor behaviors in batteries, it is still at the early stage in this field and more efforts are necessary to further understand its inherent working mechanism.

\section{Formation of solid electrolyte interphase layer in SIBS}

The reactivity of electrode materials with electrolytes is one of the most important factors influencing the electrochemical performance of batteries. The most significant surface chemical modifications occur usually on the negative electrode materials due to reductive decomposition of electrolyte at low potentials and formation of passive layer called a SEI layer described for the first time as a phenomenon occurring in LIBs by Peled [160]. The mechanisms of formation, the properties of the SEI layer were widely discussed for LIBs especially in the case of graphite-type electrodes [161-170]. The SEI layer was much less studied on the alloying or conversiontype electrode materials used in the LIB, where the formation of SEI layer is not only limited to the first cycle but the continuous electrolyte decomposition can be observed on a new, freshly pulverized, bare electrode [171-175], which can be an explanation of a huge capacity fading. Ideally, to avoid further consumption of electrolyte, the SEI layer of alloy or conversion-type materials has to sustain higher mechanical stresses, which requires higher flexibility of this surface film. In the case of SIBs, there is limited number of studies on the SEI layer $[14,34,36,176-178]$ but as the SEI layer plays a significant role in the cycling ability of the electrode and in the battery life, it is very important to know the mechanism of the SEI layer formation and its morphological and chemical properties. The passive layer can be also formed on the cathode material but the mechanism of the cathode passivation, the layer morphology and chemistry is different and it will be not discussed here.

The chemistry of SEI layer can be significantly influenced by the type of electrolytes (salts and solvents). The most conventional electrolytes used in the SIBs are based on organic carbonate-based solvents, which can be a propylene carbonate (PC), ethylene carbonate (EC) and dimethyl carbonate (DMC), or diethyl carbonate (DEC) and sodium salts such as $\mathrm{NaClO}_{4}, \mathrm{NaPF}_{6}$, or NaTFSI. The binary (such as EC:DEC, PC:EC or EC:DMC) or even ternary solvents (such as EC:PC:DMC) [179] can be used as electrolytes in SIBs. The electrolyte not only should have good physico-chemical properties (high conductivity, low viscosity, low ion pairing) but also lead to the formation of good quality SEI layer. The same for SIBs as for LIBs. A good quality of the SEI should prevent from further electrolyte decomposition, being a good electronic insulator and a good ionic conductor. Moreover, the SEI layer should be chemically stable upon cycling and at higher temperatures, flexible, morphologically homogenous to avoid further consumption of electrolyte and capacity fading.

The SEI layer formed on the carbon anode in the SIBs is different with that in the LIBs [14]. As analysed by XPS and ToF-SIMS, it was evidenced that the surface of the SEI layer in the SIBs is composed of the $\mathrm{Na}_{2} \mathrm{CO}_{3}$ and alkyl carbonate $\mathrm{ROCO}_{2}$ but lower quantity of oxygenated and organic species was detected in the inner part of the SEI layer in comparison to the LIBs. Other studies performed on the SEI layer in SIBs showed that its composition and stability can be significantly influenced by the type of anode electrode material. The thick and homogenous SEI layer composed principally of inorganic components (carbonates and $-\mathrm{C}=\mathrm{O}$ - rich species) 
was evidenced on $\mathrm{Fe}_{2} \mathrm{O}_{3}$ electrode [180]. This different composition of the SEI layer formed in the SIBs than in the LIBs was attributed to higher reactivity of $\mathrm{Na}$ electrode, especially in the half-cell systems where the $\mathrm{Na}$ is used as a counter/reference electrode [181]. The lower reactivity of Li-based batteries allows to formation of the SEI layer rich in non-completely decomposed organic solvent molecules. In the case of Sn anode cycled in EC:DMC electrolytes, it was shown that the SEI layer is composed of $\mathrm{Na}_{2} \mathrm{O}$ and $\mathrm{Na}_{2} \mathrm{CO}_{3}$ [182] and the SEI layer thickness depends on the state of charge [178]. However, a dynamic character of the SEI layer (with thickness evolving with the state of charge/discharge) was also evidenced for the conversion and alloying-type of electrodes in LIBs [122-124,171,172]. A more significant proportion of inorganic compounds vs organic compounds was found in the SEI layer formed on the $\mathrm{Sb}$ anode electrode [36], which confirmed the study performed by Komaba et al. [14] The salt degradation leads to formation of $\mathrm{eNaClO}_{4}, \mathrm{NaClO}_{3}$ and $\mathrm{NaCl}$ [36]. However, it was found that the SEI layer formed on the Sb anode is thinner when cycled vs Na that the SEI layer formed on the $\mathrm{Sb}$ anode cycled vs $\mathrm{Li}$. The lower thickness was explained by less significant electrolyte degradation due to the higher $\mathrm{Na}^{+} / \mathrm{Na}$ potential than that of $\mathrm{Li}+/ \mathrm{Li}$ or more significant dissolution of the SEI species in SIBs [183]. However, the lower thickness can be also attributed to different solvents used in these two systems (PC-based electrolytes used in the case of SIB and PC:EC:DMC mixture in the case of LIB). It should be emphasized this thinner SEI layer formed on Sb anode in the SIBs, having also a slightly different composition that the SEI layer formed on Sb anode in LIB had the excellent influence on the system cyclability.

(a)

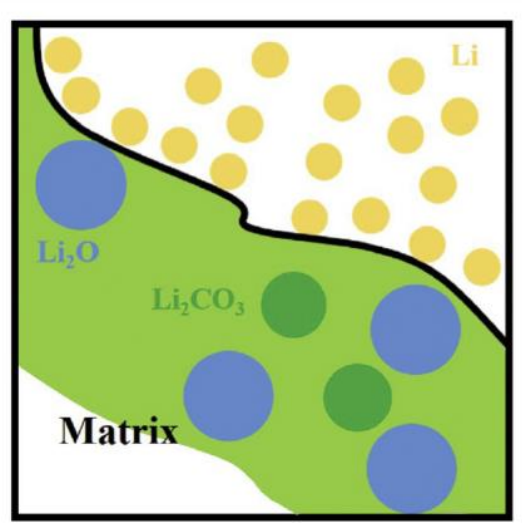

(b)

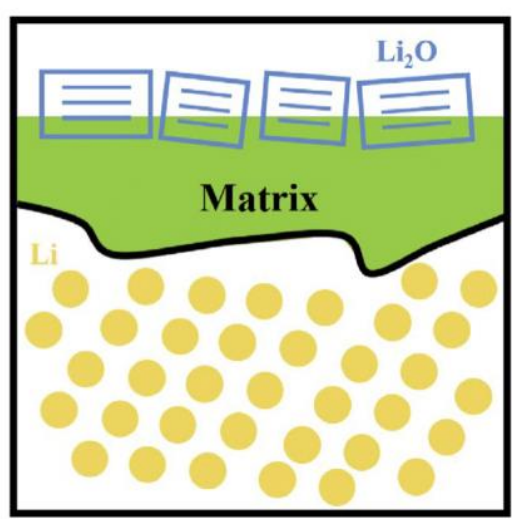

Fig. 11. The schematic illustration of (a) mosaic-type model and (b) multilayer model for SEI.

In order to improve the quality of the SEI layer different electrolyte additives can be used such as vinylene carbonate (VC) and fluoroethylene carbonate (FEC) [14]. They can be particularly useful in formation of stable SEI layer on anode materials undergoing big volume changes such as conversion- or alloying-type electrode materials. VC and FEC contribute to formation of flexible long chain polycarbonates, which participating in formation of stable SEI layer can accommodate volume changes and thus improve the cycle life of SIBs based on Sb-based anodes [184] or hard carbons [14]. The authors found that the most effective additive improving the long-term cycling of SIBs is FEC (2\%) and no significant improvement was observed 
for additives such as vinylene carbonate (VC), transdifluoroetyhene carbonate (DFEC) or ethylene sulfite (ES). The later studies confirmed the beneficial effect of FEC principally for alloying and conversion type electrode materials [27,68,176] and not really for hard carbon electrode [185]. As mentioned by Bommier et al. [186], it is difficult to conclude today about the beneficial effect of FEC or any kind of additive on the cycle life of SIB. The reactivity of electrolyte/additive seems to be significantly influenced by type of electrode material. The comparison of different studies is difficult due to variation of different parameters in tested SIBs. An interesting assessment of quantitative analysis of these different parameters was presented in a review paper by Bommier et al. [186] It should be noted also that the formation of the SEI layer can be also strongly influenced by the type of cell: half vs full cell. In the case of half-cell setup, a significant reactivity of $\mathrm{Na}$ counter electrode with carbonated-based electrolytes was noticed [185,187]. These studies proved that important attention should be paid when studying the electrochemical performance of SIB, where the reactivity of electrolyte vs the electrode materials (even $\mathrm{Na}$ counter electrode) is much more important than in the case of Li-based systems. It is encouraging that Cui group [188] characterized the atomic structure of SEI on Li metal by cryo-electron microscopy recently. Under cryogenic conditions ( 170 C), the battery materials could remain pristine. Based on these exciting facts, they compared the composition and component distribution of SEI formed in the common carbonate-based electrolytes with FEC and without FEC. It was found that inorganic components $\left(\mathrm{Li}_{2} \mathrm{CO}_{3}\right.$ and $\left.\mathrm{Li}_{2} \mathrm{O}\right)$ distributed randomly throughout the SEI formed in the electrolyte without FEC. This random structure can be descripted by mosaic-type model (Fig.11a). Conversely, instead of a random distribution of inorganic components, the SEI formed in the presence of FEC is more ordered and appears to have a multilayer structure, consistent with the multilayer model system (Fig. 11b). Thereafter, combing with that the batteries perform better in the presence of FEC, Cui group hypothesize that the ordered property of a multilayer structure can ensure increased mechanical durability, making it more robust during battery cycling, whereas a random distribution of inorganics is more likely to collapse during cycling. Though Cui group's research object is Li metal, the experiences obtained from it would enlighten the SEI research in SIBs.

In short, more systematic studies on influence of different cell parameters on the formation and stability of the SEI layer in SIBs would significantly help in their development. The electrochemical performance, the ageing of the electrode materials and/ or battery systems are governed by the sodiation/desodiation processes as well as the interfacial processes associated with the formation of the SEI layer. The choice of the solvent/salt/additive should be carefully considered as a function of type of electrode materials.

\section{Conclusions and outlook}

This review summarizes the recent developments of high-rate and long-term cycling anode materials for sodium-ion batteries. Considering the relatively low specific theoretical capacity of insertion-type anodes, materials with high theoretical capacity relied on alloy and conversion reaction are more likely the future direction of the anode materials of SIBs. The biggest drawback of alloy- and conversion-based materials is their severe volume change upon cycling. Herein, the reaction mechanisms and approaches to improve the electrochemical performance of alloy- and conversion-based materials are discussed, including designing nanostructured frameworks (e.g., nanosheets, nanowires, nanoarrays), introducing carbon materials (e.g., graphene, carbon nanotubes, mesoporous carbon spheres) into the system and designing intermetallic compounds. The great progress has been accomplished by engineering nanostructured materials. 
Nanoarchitectured array electrodes have been demonstrated to exhibit superior electrochemical performance. This novel architecture can provide the fast transport highways for both ion and electron diffusion, the strong adhesion between the active material and the current collector, and the void spaces. The strong adhesion and the void spaces would help to impede the pulverization and collapse and accommodate the drastic volume variations, respectively.

However, most of the available approaches to synthesize nano-architectured arrays are too complicated to be applied in commercial production. There is still a large gap in material synthesis between the laboratory route and the industrial route. Therefore, it is imperative to develop some simple, facile and cost-effective methods such as balling milling or solution-chemistry route to synthesize such nano-material anodes with high yield and environmental friendliness for the sake of using them for SIBs. Furthermore, though involving carbon-based materials is also regarded as an effective way to facilitate the electrical conductivity and to buffer the volume fluctuation, the overall capacity density of the anode would be reduced due to the excessive carbon ratio. Regarding the contradiction brought by carbon contents, sodium-ion batteries can learn from the experience of lithium-ion battery advancements, that is, developing the next generation binder with the features of high ion/ electron conductivity, good stretchable ability and superior adhesion capability. Nowadays, the most commonly used binder in both lithium-ion batteries and sodium-ion batteries is poly (vinylidene fluoride) (PVDF), which seems to be behind the requirement for alloying- and conversion-typeanode materials with the huge volume change. Some novel binders such as lithium-polyacrylic acid (LiPAA), polyacrylic acid containing polyrotaxane and poly (3,4-ethylened ioxythiophene): polystyrene sulfonate (PEDOT:PSS) based polymers have shown the enhanced performance in LIBs compared with the conventional binder. It can be predicted that it is also very promising to transplant these experiences to SIBs. Besides, it should be noted that the detailed mechanisms of alloy- and conversion-based materials are not clearly understood yet. We still have a long way to go on this issue. DFT theoretical study is a suitable approach in energy storage research, as shown here above. It will help in understanding the working mechanisms of sodiation/desodiation and the reactivity of new electrode materials with electrolytes. In addition, the low initial Coulombic efficiency isa tough nut,which should bepaid more attention to. Similar to LIBs, pre-sodiation is an effective way to improve the initial Coulombic efficiency. In terms of the intrinsic properties of materials, the good conductivity is a key factor in achieving the high initial Coulombic efficiency. What's more, the electrolyte, determining the working window and the stability of SEI layer, is another crucial component for sodium-ion batteries. In order to promote the development of sodium-ion batteries, exploring new electrolytes which possess the wider working voltage potential and adopting some additives (e.g., FEC) which is beneficial for forming the stable SEI layer as well as the uniformly distributed inorganic components are also the way researchers should continue to strive for.

\section{Acknowledgement}

The authors acknowledge financial support from the Natural Science Foundation of China (Grant no. 21673091) and from the NSFC Major International (Regional) Joint Research Project NSFCSNSF (Grant no. 51661135023). This project was also funded by Open Research Fund of Key Laboratory of the Ministry of Education for Advanced Catalysis Materials and Zhejiang Key Laboratory for Reactive Chemistry on Solid Surfaces of Zhejiang Normal University, the Natural Science Foundation of Hubei Province (No: 2015CFA125), the Fundamental Research Funds for the Central Universities of Huazhong University of Science \& Technology (2018KFYXKJC034), and the Double first-class research funding of China-Eu Institute for Clean and Renewable Energy (3011187029). 


\section{References}

[1] H. Pan, Y. Hu, L. Chen, Energy Environ. Sci. 6 (2013) 2338.

[2] J. Deng, W. Luo, S. Chou, H. Liu, S. Dou, Adv. Energy Mater. 8 (2018) 1701428. [3] A. Eftekhari, ACS Sustainable Chemistry \& Engineering, 2018.

[4] K. Nobuhara, H. Nakayama, M. Nose, S. Nakanishi, H. Iba, J. Power Sources 243 (2013) 585e587.

[5] B. Jache, P. Adelhelm, Angew. Chem., Int. Ed. Engl. 53 (2014) 10169e10173.

[6] H. Kim, J. Hong, Y. Park, J. Kim, I. Hwang, K. Kang, Adv. Funct. Mater. 25 (2015) 534e541.

[7] P. Ge, H. Hou, X. Cao, S. Li, G. Zhao, T. Guo, C. Wang, X. Ji, Adv. Sci. 5 (2018) 1800080.

[8] H. Hou, L. Shao, Y. Zhang, G. Zou, J. Chen, X. Ji, Adv. Sci. 4 (2017) 1600243.

[9] G. Zhao, Y. Zhang, G. Zou, Y. Zhang, W. Hong, Y. Jiang, W. Xu, H. Shuai, H. Hou, X. Ji, J. Mater. Chem.

A 6 (2018) 11488e11495.

[10] Y. Zhang, C. Wang, H. Hou, G. Zou, X. Ji, Adv. Energy Mater. 7 (2017) 1600173. [11] F. Xie, L. Zhang,

D. Su, M. Jaroniec, S. Qiao, Adv. Mater. 29 (2017).

[12] L. Gao, L. Wang, S. Dai, M. Cao, Z. Zhong, Y. Shen, M. Wang, J. Power Sources 344 (2017) $223 e 232$.

[13] Z. Jian, L. Zhao, H. Pan, Y. Hu, H. Li, W. Chen, L. Chen, Electrochem. Commun. 14 (2012) 86e89.

[14] S. Komaba, W. Murata, T. Ishikawa, N. Yabuuchi, T. Ozeki, T. Nakayama, A. Ogata, K. Gotoh, F. K, Adv.

Funct. Mater. 21 (2011) 3859e3867.

[15] Y. Li, Y. Hu, H. Li, L. Chen, X. Huang, J. Mater. Chem. A 4 (2016) 96e104.

[16] Y. Li, S. Xu, X. Wu, J. Yu, Y. Wang, Y. Hu, H. Li, L. Chen, X. Huang, J. Mater. Chem. A 3 (2015) 71 e77.

[17] H. Pan, X. Lu, X. Yu, Y. Hu, H. Li, X. Yang, L. Chen, Adv. Energy Mater. 3 (2013) 1186e1194.

[18] P. Senguttuvan, G. Rousse, V. Seznec, J. Tarascon, M. Palacín, Chem. Mater. 23 (2011) 4109 e4111.

[19] D. Stevens, J. Dahn, J. Electrochem. Soc. 147 (2000) 1271e1273.

[20] Y. Sun, L. Zhao, H. Pan, X. Lu, L. Gu, Y. Hu, H. Li, M. Armand, Y. Ikuhara, L. Chen, X. Huang, Nat. Commun. 4 (2013) 1870.

[21] Y. Wang, R. Xiao, Y. Hu, M. Avdeev, L. Chen, Nat. Commun. 6 (2015) 6954.

[22] Y. Wang, X. Yu, S. Xu, J. Bai, R. Xiao, Y. Hu, H. Li, X. Yang, L. Chen, X. Huang, Nat. Commun. 4 (2013) 2365.

[23] T. Yi, L. Jiang, J. Shu, C. Yue, R. Zhu, H. Qiao, J. Phys. Chem. Solid. 71 (2010) $1236 e 1242$.

[24] C. Dette, M. Perez-Osorio, C. Kley, P. Punke, C. Patrick, P. Jacobson, F. Giustino, S. Jung, K. Kern, Nano Lett. 14 (2014) 6533e6538.

[25] N. Yabuuchi, K. Kubota, M. Dahbi, S. Komaba, Chem. Rev. 114 (2014) 11636e11682.

[26] Y. Lim, S. Huang, Y. Zhang, D. Kong, Y. Wang, L. Guo, J. Zhang, Y. Shi, T. Chen, L. Ang, H. Yang, Energy Stor. Mater. 15 (2018) 98e107.

[27] A. Darwiche, C. Marino, M. Sougrati, B. Fraisse, L. Stievano, L. Monconduit, J. Am. Chem. Soc. 134 (2012) $20805 \mathrm{e} 20811$.

[28] Y. Zhu, Y. Wen, X. Fan, T. Gao, F. Han, C. Luo, S. Liou, C. Wang, ACS Nano 9 (2015) 3254 e3264.

[29] Y. Xu, M. Zhou, Y. Lei, Adv. Energy Mater. 6 (2016) 1502514.

[30] M. Wang, F. Zhang, C. Lee, Y. Tang, Adv. Energy Mater. 7 (2017) 1700536.

[31] Y. Kim, K. Ha, S. Oh, K. Lee, Chem. Eur J. 20 (2014) 11980e11992.

[32] V. Chevrier, G. Ceder, J. Electrochem. Soc. 158 (2011) A1011.

[33] W. Luo, F. Shen, C. Bommier, H. Zhu, X. Ji, L. Hu, Acc. Chem. Res. 49 (2016) 231 e240.

[34] A. Darwiche, L. Bodenes, L. Madec, L. Monconduit, H. Martinez, Electrochim. Acta 207 (2016) 284 e292. 
[35] V. Winkler, G. Kilibarda, S. Schlabach, D. Szabo, T. Hanemann, M. Bruns, J. Phys. Chem. C 120 (2016) $24706 \mathrm{e} 24714$.

[36] L. Bodenes, A. Darwiche, L. Monconduit, H. Martinez, J. Power Sources 273 (2015) 14e24.

[37] Y. Zhang, H. Wang, Z. Luo, H. Tan, B. Li, S. Sun, Z. Li, Y. Zong, Z. Xu, Y. Yang, K. Khor, Q. Yan, Adv. Energy Mater. 6 (2016) 1600453.

[38] L. Wu, X. Hu, J. Qian, F. Pei, F. Wu, R. Mao, X. Ai, H. Yang, Y. Cao, Energy Environ. Sci. 7 (2014) $323 \mathrm{e} 328$.

[39] H. Kim, H. Kim, Z. Ding, M. Lee, K. Lim, G. Yoon, K. Kang, Adv. Energy Mater. 6 (2016) 1600943.

[40] A. Kohandehghan, K. Cui, M. Kupsta, J. Ding, E. Lotfabad, W. Kalisvaart, D. Mitlin, Nano Lett. 14 (2014) $5873 e 5882$.

[41] Y. Liu, Y. Xu, Y. Zhu, J. Culver, C. Lundgren, K. Xu, C. Wang, ACS Nano 7 (2013)

3627 e3634.

[42] J. Sun, G. Zheng, H. Lee, N. Liu, H. Wang, H. Yao, W. Yang, Y. Cui, Nano Lett. 14 (2014) 4573 e4580.

[43] N. Zhang, X. Han, Y. Liu, X. Hu, Q. Zhao, J. Chen, Adv. Energy Mater. 5 (2015) 1401123.

[44] S. Yuan, X. Huang, D. Ma, H. Wang, F. Meng, X. Zhang, Adv. Mater. 26 (2014) 2273e2279, 2284.

[45] Y. Lu, P. Zhou, K. Lei, Q. Zhao, Z. Tao, J. Chen, Adv. Energy Mater. 7 (2017) 1601973.

[46] X. Wang, K. Chen, G. Wang, X. Liu, H. Wang, ACS Nano $11 \quad$ (2017)

$11602 \mathrm{e} 11616$.

[47] M. Fan, Y. Chen, Y. Xie, T. Yang, X. Shen, N. Xu, H. Yu, C. Yan, Adv. Funct.

Mater. 26 (2016) 5019e5027.

[48] L. David, R. Bhandavat, G. Singh, ACS Nano 8 (2014) 1759e1770.

[49] Y. Liu, X. He, D. Hanlon, A. Harvey, J. Coleman, Y. Li, ACS Nano 10 (2016) 8821e8828.

[50] Z. Hu, Z. Zhu, F. Cheng, K. Zhang, J. Wang, C. Chen, J. Chen, Energy Environ. Sci. 8 (2015) 1309e1316.

[51] S. Li, Y. Wang, J. Qiu, M. Ling, H. Wang, W. Martens, S. Zhang, RSC Adv. 4 (2014) 50148e50152.

[52] M. Hu, Y. Jiang, W. Sun, H. Wang, C. Jin, M. Yan, ACS Appl. Mater. Interfaces 6 (2014) 19449e19455.

[53] Y. Liu, H. Kang, L. Jiao, C. Chen, K. Cao, Y. Wang, H. Yuan, Nanoscale 7 (2015) 1325e1332.

[54] Y. Lin, P. Abel, A. Gupta, J. Goodenough, A. Heller, C. Mullins, ACS Appl. Mater. Interfaces 5 (2013) 8273 e8277.

[55] W. Li, S. Chou, J. Wang, J. Kim, H. Liu, S. Dou, Adv. Mater. 26 (2014) 4037e4042.

[56] Y. Yui, Y. Ono, M. Hayashi, Y. Nemoto, K. Hayashi, K. Asakura, H. Kitabayashi, J. Electrochem. Soc. 162 (2015) A3098eA3102.

[57] L. Baggetto, H. Hah, J. Jumas, C. Johnson, J. Johnson, J. Keum, C. Bridges, G. Veith, J. Power Sources 267 (2014) 329e336.

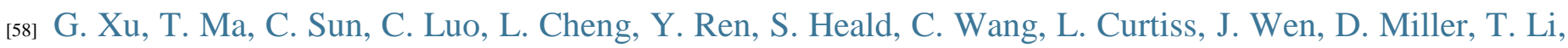
X. Zuo, V. Petkov, Z. Chen, K. Amine, Nano Lett. 16 (2016) $2663 e 2673$.

[59] Y. Ko, S. Choi, Y. Kang, ACS Appl. Mater. Interfaces 8 (2016) 6449e6456.

[60] C. Yang, S. Xin, Y. Yin, H. Ye, J. Zhang, Y. Guo, Angew. Chem. 125 (2013) 8521e8525.

[61] K. Zhang, Z. Hu, X. Liu, Z. Tao, J. Chen, Adv. Mater. 27 (2015) 3305e3309.

[62] Y. Xiao, S. Lee, Y. Sun, Adv. Energy Mater. 7 (2017) 1601329.

[63] S. Komaba, Y. Matsuura, T. Ishikawa, N. Yabuuchi, W. Murata, S. Kuze, Electrochem. Commun. 21 (2012) $65 \mathrm{e} 68$.

[64] L. Ellis, T. Hatchard, M. Obrovac, J. Electrochem. Soc. $159 \quad$ (2012) A1801eA1805. 
[65] J. Wang, X. Liu, S. Mao, J. Huang, Nano Lett. 12 (2012) 5897e5902.

[66] D. Nam, T. Kim, K. Hong, H. Kwon, ACS Nano 8 (2014) 11824e11835.

[67] D. Nam, K. Hong, S. Lim, T. Kim, H. Kwon, J. Phys. Chem. C 118 (2014) 20086e20093.

[68] H. Zhu, Z. Jia, Y. Chen, N. Weadock, J. Wan, O. Vaaland, X. Han, T. Li, L. Hu, Nano Lett. 13 (2013) $3093 \mathrm{e} 3100$.

[69] Y. Liu, N. Zhang, L. Jiao, Z. Tao, J. Chen, Adv. Funct. Mater. 25 (2015) 214e220. [70] Y. Liu, N. Zhang, L. Jiao, J. Chen, Adv. Mater. 27 (2015) $6702 \mathrm{e} 6707$.

[71] Y. Jeon, X. Han, K. Fu, J. Dai, J. Kim, L. Hu, T. Song, U. Paik, J. Mater. Chem. A 4 (2016) 18306e18313. ${ }_{[72]}$ M. Sheng, F. Zhang, B. Ji, X. Tong, Y. Tang, Adv. Energy Mater. 7 (2017) 1601963.

[73] J. Sun, H. Lee, M. Pasta, Y. Sun, W. Liu, Y. Li, H. Lee, N. Liu, Y. Cui, Energy Storage Materials 4 (2016) $130 \mathrm{e} 136$.

[74] J. Qian, X. Wu, Y. Cao, X. Ai, H. Yang, Angew. Chem., Int. Ed. Engl. 52 (2013) 4633e4636.

[75] J. Sun, H. Lee, M. Pasta, H. Yuan, G. Zheng, Y. Sun, Y. Li, Y. Cui, Nat. Nanotechnol. 10 (2015) 980e985. [76] Y. Kim, Y. Park, A. Choi, N. Choi, J. Kim, J. Lee, J. Ryu, S. Oh, K. Lee, Adv. Mater. 25 (2013) 3045e3049. [77] H. Gao, T. Zhou, Y. Zheng, Y. Liu, J. Chen, H. Liu, Z. Guo, Adv. Energy Mater. 6 (2016) 1601037.

${ }^{[78]}$ Y. Liu, A. Zhang, C. Shen, Q. Liu, X. Cao, Y. Ma, L. Chen, C. Lau, T. Chen, F. Wei, C. Zhou, ACS Nano 11 (2017) 5530e5537.

[79] W. Li, Z. Yang, M. Li, Y. Jiang, X. Wei, X. Zhong, L. Gu, Y. Yu, Nano Lett. 16 (2016) 1546e1553.

[80] H. Zhou, S. Kitagawa, Chem. Soc. Rev. 43 (2014) 5415e5418.

[81] Y. Zhao, Z. Song, X. Li, Q. Sun, N. Cheng, S. Lawes, X. Sun, Energy Storage Materials 2 (2016) 35e62.

[82] H. Jiang, B. Liu, Y. Lan, K. Kuratani, T. Akita, H. Shioyama, F. Zong, Q. Xu, J. Am. Chem. Soc. 133 (2011) $11854 \mathrm{e} 11857$.

[83] J. Cravillon, R. Nayuk, S. Springer, A. Feldhoff, K. Huber, M. Wiebcke, Chem.

Mater. 23 (2011) 2130e2141.

[84] Y. Xue, Q. Zhang, T. Zhang, L. Fu, ChemNanoMat 3 (2017) 352e361.

${ }^{[85]}$ K. Hembram, H. Jung, B. Yeo, S. Pai, S. Kim, K. Lee, S. Han, J. Phys. Chem. C 119 (2015) 15041 e15046.

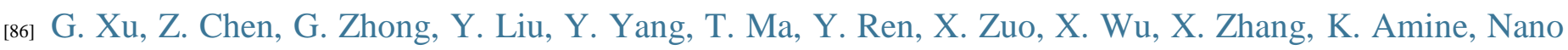
Lett. 16 (2016) 3955e3965.

[87] W. Lei, V. Mochalin, D. Liu, S. Qin, Y. Gogotsi, Y. Chen, Nat. Commun. 6 (2015) 8849.

${ }_{\text {[88] }}$ C. Ryder, J. Wood, S. Wells, Y. Yang, D. Jariwala, T. Marks, G. Schatz, M. Hersam, Nat. Chem. 8 (2016) 597 e602.

[89] Y. Zhao, H. Wang, H. Huang, Q. Xiao, Y. Xu, Z. Guo, H. Xie, J. Shao, Z. Sun, W. Han, X. Yu, P. Li, P. Chu, Angew. Chem., Int. Ed. Engl. 55 (2016) 5003e5007.

[90] Y. Deng, Z. Luo, N. Conrad, H. Liu, Y. Gong, S. Najmaei, P. Ajayan, J. Lou, X. Xu, P. Ye, ACS Nano 8 (2014) 8292e8299.

[91] L. Li, Y. Yu, G. Ye, Q. Ge, X. Ou, H. Wu, D. Feng, X. Chen, Y. Zhang, Nat. Nanotechnol. 9 (2014) 372 e377. [92] M. Batmunkh, M. Bat-Erdene, J. Shapter, Adv. Mater. 28 (2016) 8586e8617. [93] J. Brent, N. Savjani, E. Lewis, S. Haigh, D. Lewis, P. O'Brien, Chem. Commun. (Camb) 50 (2014) 13338e13341.

[94] Z. Huang, H. Hou, Y. Zhang, C. Wang, X. Qiu, X. Ji, Adv. Mater. 29 (2017).

[95] H. Hou, M. Jing, Y. Yang, Y. Zhang, W. Song, X. Yang, J. Chen, Q. Chen, X. Ji, J. Power Sources 284 (2015) $227 \mathrm{e} 235$. 
[96] M. He, K. Kravchyk, M. Walter, M. Kovalenko, Nano Lett. 14 (2014) $1255 \mathrm{e} 1262$.

[97] L. Baggetto, P. Ganesh, C. Sun, R. Meisner, T. Zawodzinski, G. Veith, J. Mater. Chem. A 1 (2013) 7985.

[98] P. Allan, J. Griffin, A. Darwiche, O. Borkiewicz, K. Wiaderek, K. Chapman, A. Morris, P. Chupas, L. Monconduit, C. Grey, J. Am. Chem. Soc. 138 (2016) $2352 \mathrm{e} 2365$.

[99] H. Hou, M. Jing, Y. Yang, Y. Zhu, L. Fang, W. Song, C. Pan, X. Yang, X. Ji, ACS Appl. Mater. Interfaces 6 (2014) 16189e16196.

[100] L. Wu, H. Lu, L. Xiao, X. Ai, H. Yang, Y. Cao, J. Mater. Chem. A 3 (2015) 5708e5713.

[101] J. Duan, W. Zhang, C. Wu, Q. Fan, W. Zhang, X. Hu, Y. Huang, Nanomater. Energy 16 (2015) 479 e487.

[102] T. Wu, H. Hou, C. Zhang, P. Ge, Z. Huang, M. Jing, X. Qiu, X. Ji, ACS Appl. Mater. Interfaces 9 (2017) $26118 \mathrm{e} 26125$.

[103] F. Wan, H. Lü, X. Zhang, D. Liu, J. Zhang, X. He, X. Wu, J. Alloy. Comp. 672 (2016) 72 e78.

[104] H. Lü, F. Wan, L. Jiang, G. Wang, X. Wu, Part. Part. Syst. Char. 33 (2016) 204e211.

[105] S. Qiu, X. Wu, L. Xiao, X. Ai, H. Yang, Y. Cao, ACS Appl. Mater. Interfaces 8 (2016) 1337e1343.

[106] G. Wang, X. Xiong, Z. Lin, C. Yang, Z. Lin, M. Liu, Electrochim. Acta 242 (2017) 159e164.

[107] H. Liu, M. Jia, N. Sun, B. Cao, R. Chen, Q. Zhu, F. Wu, N. Qiao, B. Xu, ACS Appl. Mater. Interfaces 7 (2015) 27124e27130.

[108] J. Xu, M. Wang, N. Wickramaratne, M. Jaroniec, S. Dou, L. Dai, Adv. Mater. 27 (2015) $2042 \mathrm{e} 2048$.

[109] J. Gu, Z. Du, C. Zhang, J. Ma, B. Li, S. Yang, Adv. Energy Mater. 7 (2017) 1700447.

[110] F. Zhang, C. Xia, J. Zhu, B. Ahmed, H. Liang, D. Velusamy, U. Schwingenschlo€gl, H. Alshareef, Adv. Energy Mater. 6 (2016) 1601188.

[111] M. Walter, S. Doswald, M. Kovalenko, J. Mater. Chem. A 4 (2016) $7053 \mathrm{e} 7059$.

[112] W. Zhang, J. Mao, W. Pang, Z. Guo, Z. Chen, Electrochim. Acta 235 (2017) 107e113.

[113] D. Lan, W. Wang, L. Shi, Y. Huang, L. Hu, Q. Li, J. Mater. Chem. A 5 (2017) 5791e5796.

[114] H. Xie, W. Kalisvaart, B. Olsen, E. Luber, D. Mitlin, J. Buriak, J. Mater. Chem. A 5 (2017) 9661 e9670.

[115] J. Kim, D. Kim, Chem. Asian J. 9 (2014) 3313e3318.

[116] Y. Mun, Y. Yoon, J. Hur, M. Park, J. Bae, J. Kim, Y. Yoon, I. Yoo, S. Lee, I. Kim, J. Power Sources 362 (2017) 115 e122.

[117] E. Jackson, S. Green, A. Prieto, ACS Appl. Mater. Interfaces 7 (2015) 7447 e 7450 .

[118] W. Li, Q. Yang, S. Chou, J. Wang, H. Liu, J. Power Sources 294 (2015) 627e632.

[119] Z. Li, L. Zhang, X. Ge, C. Li, S. Dong, C. Wang, L. Yin, Nanomater. Energy 32 (2017) 494e502.

[120] C. Chan, H. Peng, G. Liu, K. Mcllwrath, X. Zhang, R. Huggins, Y. Cui, Nat. Nanotechnol. 3 (2008) $31 \mathrm{e} 35$.

[121] B. Tian, J. Swiatowska, V. Maurice, S. Zanna, A. Seyeux, P. Marcus, Appl. Surf. Sci. 353 (2015) $1170 \mathrm{e} 1178$.

[122] F. Liao, J. Swiatowska, V. Maurice, A. Seyeux, L. Klein, S. Zanna, P. Marcus, Phys. Chem. Chem. Phys. 17 (2015) 619e629.

[123] B. Tian, J. Swiatowska, V. Maurice, S. Zanna, A. Seyeux, L. Klein, P. Marcus, Langmuir 30 (2014) $3538 \mathrm{e} 3547$.

[124] F. Liao, J. Swiatowska, V. Maurice, A. Seyeux, L. Klein, S. Zanna, P. Marcus, Appl. Surf. Sci. 283 (2013) 888 e899. 
[125] X. Wang, X. Zhou, K. Yao, J. Zhang, Z. Liu, Carbon 49 (2011) 133 e139.

[126] J. Liang, W. Wei, D. Zhong, Q. Yang, L. Li, L. Guo, ACS Appl. Mater. Interfaces 4 (2012) 454e459.

[127] X. Zhou, L. Wan, Y. Guo, Adv. Mater. 25 (2013) 2152e2157.

[128] S. Yang, W. Yue, J. Zhu, Y. Ren, X. Yang, Adv. Funct. Mater. 23 (2013) 3570e3576.

[129] M. Gu, A. Kushima, Y. Shao, J. Zhang, J. Liu, N. Browning, J. Li, C. Wang, Nano Lett. 13 (2013) $5203 e 5211$.

[130] Y. Liu, X. Fang, M. Ge, J. Rong, C. Shen, A. Zhang, H. Enaya, C. Zhou, Nanomater. Energy 16 (2015) $399 \mathrm{e} 407$.

[131] P. Gao, L. Wang, Y. Zhang, Y. Huang, K. Liu, ACS Nano 9 (2015) 11296e11301.

${ }^{[132]}$ Y. Zhao, X. Li, B. Yan, D. Li, S. Lawes, X. Sun, J. Power Sources 274 (2015) 869e884.

[133] X. Xie, D. Su, J. Zhang, S. Chen, A. Mondal, G. Wang, Nanoscale 7 (2015) 3164e3172.

[134] L. Fan, X. Li, B. Yan, J. Feng, D. Xiong, D. Li, L. Gu, Y. Wen, S. Lawes, X. Sun, Adv.

Energy Mater. 6 (2016) 1502057.

[135] X. Wang, X. Shen, Z. Wang, R. Yu, C. L, ACS Nano 8 (2014) 11394e11400.

[136] C. Zhu, X. Mu, P. Aken, Y. Yu, J. Maier, Angew. Chem., Int. Ed. Engl. 53 (2014) 2152e2156.

[137] D. Su, S. Dou, G. Wang, Adv. Energy Mater. 5 (2015) 1401205.

[138] S. Choi, Y. Ko, J. Lee, Y. Kang, Adv. Funct. Mater. 25 (2015) 1780e1788.

[139] X. Xie, Z. Ao, D. Su, J. Zhang, G. Wang, Adv. Funct. Mater. 25 (2015) 1393e1403.

[140] H. Zhu, F. Zhang, J. Li, Y. Tang, Small 14 (2018) 1703951.

[141] S. Choi, Y. Kang, Nanoscale 7 (2015) 3965 e3970.

[142] W. Ryu, H. Wilson, S. Sohn, J. Li, X. Tong, E. Shaulsky, J. Schroers, M. Elimelech, A. Taylor, ACS Nano 10 (2016) 3257 e3266.

[143] Y. Wang, D. Kong, W. Shi, B. Liu, G. Sim, Q. Ge, H. Yang, Adv. Energy Mater. 6 (2016) 1601057.

${ }_{[144]}$ Y. Ding, P. Kopold, K. Hahn, P. Aken, J. Maier, Y. Yu, Adv. Mater. 28 (2016) 7774e7782.

[145] J. Li, X. Shi, J. Fang, J. Li, Z. Zhang, ChemNanoMat 2 (2016) 997e1002.

[146] W. Chen, S. Qi, M. Yu, X. Feng, S. Cui, J. Zhang, L. Mi, Electrochim. Acta 230 (2017) 1e9.

[147] S. Yao, J. Cui, Z. Lu, Z. Xu, L. Qin, J. Huang, Z. Sadighi, F. Ciucci, J. Kim, Adv. Energy Mater. 7 (2017) 1602149.

[148] G. Zou, H. Hou, G. Zhao, P. Ge, D. Yin, X. Ji, J. Mater. Chem. A 6 (2018) 4839e4847.

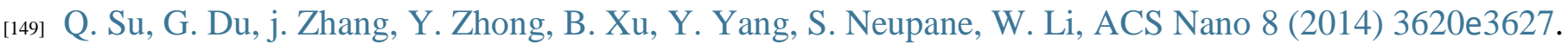

[150] G. Zhao, Y. Zhang, L. Yang, Y. Jiang, Y. Zhang, W. Hong, Y. Tian, H. Zhao, J. Hu, L. Zhou, H. Hou,

X. Ji, L. Mai, Adv. Funct. Mater. 28 (2018) 1803690.

[151] P. Ge, C. Zhang, H. Hou, B. Wu, L. Zhou, S. Li, T. Wu, J. Hu, L. Mai, X. Ji, Nanomater. Energy 48 (2018) 617 e629.

[152] V. Augustyn, P. Simon, B. Dunn, Energy Environ. Sci. 7 (2014) 1597.

[153] T. Brezesinski, J. Wang, S. Tolbert, B. Dunn, Nat. Mater. 9 (2010) 146e151.

[154] P. Simon, Y. Gogotsi, B. Dunn, Science 343 (2014) 1210e1211.

${ }_{[155]}$ H. Kim, J. Cook, S. Tolbert, B. Dunn, J. Electrochem. Soc. 162 (2015) A5083eA5090.

[156] S. Li, J. Qiu, C. Lai, M. Ling, H. Zhao, S. Zhang, Nanomater. Energy 12 (2015) 224e230.

${ }^{[157]}$ D. Chao, C. Zhu, P. Yang, X. Xia, J. Liu, J. Wang, X. Fan, S. Savilov, J. Lin, H. Fan, Z. Shen, Nat. Commun. 7 (2016) 12122. 
[158] L. Li, S. Peng, N. Bucher, H. Chen, N. Shen, A. Nagasubramanian, E. Eldho, S. Hartung, S. Ramakrishna, M. Srinivasan, Nanomater. Energy 37 (2017) 81e89.

[159] C. Zhao, C. Yu, M. Zhang, H. Huang, S. Li, X. Han, Z. Liu, J. Yang, W. Xiao, J. Liang, X. Sun, J. Qiu, Adv. Energy Mater. 7 (2017) 1602880. [160] E. Peled, J. Electrochem. Soc. 126 (1979) 2047e2051.

[161] A. Chagnes, J. Swiatowska, Electrolyte and solid-electrolyte interphase layer in lithium ion batteries - new developments, in: I. Belharouak (Ed.), INTECH, 2012, pp. 145e172.

[162] E. Peled, D. Golodnitsky, SEI on lithium graphite, disordered carbons and tinbased alloys, in: P.B. Balbuena, Y. Wang (Eds.), Lithium-ion Batteries: Solidelectrolyte Interphase, Imperial College Press, 2004 (Chapter 1).

[163] K. Edstrom, M. Herstedt, D. Abraham, J. Power Sources 153 (2006) 38€ 0e384.

[164] H. Bryngelsson, M. Stjerndahl, T. Gustafsson, K. Edstro€m, J. Power Sources 174 (2007) 970 e975.

[165] P. Verma, P. Maire, P. Novak, Electrochim. Acta 55 (2010) 6332e6341.

[166] X. Zhang, R. Kostecki, T. Richardson, J. Pugh, P. Ross, J. Electrochem. Soc. 148 (2001) A1341.

[167] J. Gnanaraj, R. Thompson, J. DiCarlo, K. Abraham, J. Electrochem. Soc. 154 (2007) A185.

[168] J. Besenhard, H. Fritz, J. Electroanal. Chem. Interfacial Electrochem. 53 (1974) $329 \mathrm{e} 333$.

[169] J. Besenhard, H. Fritz, Angew. Chem. Int. Ed. 22 (1983) 950e975.

[170] J. Besenhard, M. Winter, J. Yang, W. Biberacher, J. Power Sources 54 (1995) 228 e231.

[171] C. Pereira-Nabais, J. Swiatowska, A. Chagnes, A. Gohier, S. Zanna, A. Seyeux, P. Tran-Van, C. Cojocaru, M. Cassir, P. Marcus, J. Phys. Chem. C 118 (2014) 2919 e2928.

[172] F. Liao, J. Swiatowska, V. Maurice, A. Seyeux, L. Klein, S. Zanna, P. Marcus, Electrochim. Acta 120 (2014) 359e368.

[173] J. Li, J. Swiatowska, A. Seyeux, L. Huang, V. Maurice, S. Sun, P. Marcus, J. Power Sources 195 (2010) 8251 e8257.

[174] J. Li, J. Swiatowska, V. Maurice, A. Seyeux, L. Huang, S. Sun, P. Marcus, J. Phys. Chem. C 115 (2011) $7012 \mathrm{e} 7018$.

[175] J. Li, V. Maurice, J. Swiatowska-Mrowiecka, A. Seyeux, S. Zanna, L. Klein, S. Sun, P. Marcus, Electrochim. Acta 54 (2009) 3700 e3707.

[176] J. Qian, Y. Chen, L. Wu, Y. Cao, X. Ai, H. Yang, Chem. Commun. (Camb) 48 (2012) 7070 e7072.

[177] S. Komaba, T. Ishikawa, N. Yabuuchi, W. Murata, A. Ito, Y. Ohsawa, ACS Appl. Mater. Interfaces 3 (2011) 4165e4168.

[178] L. Kuo, A. Moradabadi, H. Huang, B. Hwang, P. Kaghazchi, J. Power Sources 341 (2017) 107e113.

[179] A. Ponrouch, R. Dedryvere, D. Monti, A. Demet, J. Mba, L. Croguennec, C. Masquelier, P. Johansson, M. Palacín, Energy Environ. Sci. 6 (2013) 2361.

[180] B. Philippe, M. Valvo, F. Lindgren, H. Rensmo, K. Edstro€m, Chem. Mater. 26 (2014) 5028 e5041.

[181] V. Oltean, B. Philippe, S. Renault, R. Duarte, H. Rensmo, D. Brandell, Chem. Mater. 28 (2016) 8742 e8751.

[182] R. Mogensen, J. Maibach, W. Brant, D. Brandell, R. Younesi, Electrochim. Acta 245 (2017) $696 \mathrm{e} 704$.

[183] M. Moshkovich, Y. Gofer, D. Aurbach, J. Electrochem. Soc. 148 (2001) E155.

[184] L. Vogt, M. Kazzi, E. Berg, S. Villar, P. Novak, C. Villevieille, Chem. Mater. 27 (2015) 1210e1216.

[185] D. Iermakova, R. Dugas, M. Palacín, A. Ponrouch, J. Electrochem. Soc. 162 (2015) A7060eA7066.

[186] C. Bommier, X. Ji, Small (2018) 1703576.

[187] C. Bommier, D. Leonard, Z. Jian, W. Stickle, P. Greaney, X. Ji, Adv. Mater. Interfaces 3 (2016) 1600449.

${ }_{[188]}$ Y. Li, Y. Li, A. Pei, K. Yan, Y. Sun, C. Wu, L. Joubert, R. Chin, A. Koh, Y. Yu, J. Perrino, B. Butz, S. Chu, Y. Cui, Science 358 (2017) 506e510. 